\title{
The Nexus Land-Use model version 1.0, an approach articulating biophysical potentials and economic dynamics to model competition for land-use
}

 \\ ${ }^{1}$ Centre International de Recherche sur l'Environnement et le Développement, Nogent-sur-Marne, France \\ ${ }^{2}$ Laboratoire des Sciences du Climat et de l'Environnement, UMR8212, Gif-sur-Yvette, France \\ ${ }^{3}$ Centre de Coopération Internationale en Recherche Agronomique pour le Développement, Montpellier, France \\ ${ }^{4}$ Potsdam Institute for Climate Impact Research, Potsdam, Germany \\ ${ }^{5}$ Institut Méditerranéen de Biodiversité et d'Ecologie marine et continentale, Aix-en-Provence, France
}

Correspondence to: F. Souty (souty@ centre-cired.fr)

Received: 23 January 2012 - Published in Geosci. Model Dev. Discuss.: 21 February 2012

Revised: 13 September 2012 - Accepted: 14 September 2012 - Published: 19 October 2012

\begin{abstract}
Interactions between food demand, biomass energy and forest preservation are driving both food prices and land-use changes, regionally and globally. This study presents a new model called Nexus Land-Use version 1.0 which describes these interactions through a generic representation of agricultural intensification mechanisms within agricultural lands. The Nexus Land-Use model equations combine biophysics and economics into a single coherent framework to calculate crop yields, food prices, and resulting pasture and cropland areas within 12 regions inter-connected with each other by international trade. The representation of cropland and livestock production systems in each region relies on three components: (i) a biomass production function derived from the crop yield response function to inputs such as industrial fertilisers; (ii) a detailed representation of the livestock production system subdivided into an intensive and an extensive component, and (iii) a spatially explicit distribution of potential (maximal) crop yields prescribed from the Lund-Postdam-Jena global vegetation model for managed Land (LPJmL). The economic principles governing decisions about land-use and intensification are adapted from the Ricardian rent theory, assuming cost minimisation for farmers. In contrast to the other land-use models linking economy and biophysics, crops are aggregated as a representative product in calories and intensification for the representative crop is a non-linear function of chemical inputs. The model equations and parameter values are first described
\end{abstract}

in details. Then, idealised scenarios exploring the impact of forest preservation policies or rising energy price on agricultural intensification are described, and their impacts on pasture and cropland areas are investigated.

\section{Introduction}

In addition to their traditional role of feeding the world, services expected from natural ecosystems and agriculture have recently extended to broader fields such as offering new energetic options, mitigating climate change or preserving biodiversity. This increasing demand for services from a finite system may generate tensions on natural resources. Decisions related to land-use must take several elements into consideration to restore multiple and conflicting demands. First, due to global environmental issues, such as climate change or loss of biodiversity, on the one hand, and to the intensification of international exchange on the other hand, land-use changes can no longer be considered as driven by local processes. Modifications of the land cover in one region of the world have an increasing impact on land-use changes in another region through price mechanisms, thus raising the need for global studies. Secondly, because they use the same limited assets, decisions or behavioural changes related to food, biomass energy, and forest preservation can interact and must therefore be assessed jointly. 


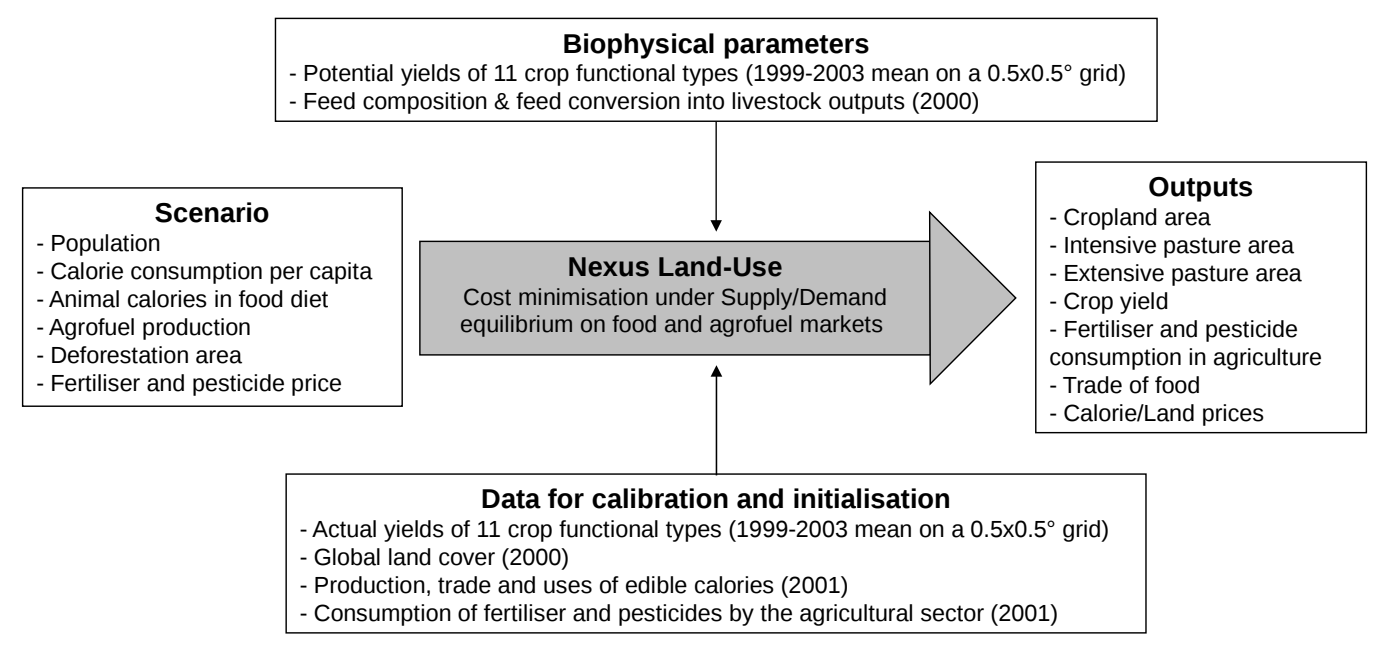

Fig. 1. Description of the modelling system. Fertiliser and pesticide consumption includes also other consumption of chemical and mineral goods.

These considerations have profoundly affected land-use modelling orientations. Originally essentially designed to evaluate local and specific issues, and characterised by the segmentation between economic and geographic approaches (Heistermann et al., 2006; Briassoulis, 2000), land-use models have progressively evolved to capture multi-scale phenomena and potential interactions with effects on land-use. To do so, two methodologies have been used. The first one consists in adapting a general equilibrium structure, mainly by improving the disaggregation of the production factors, to introduce land heterogeneity and to facilitate the calibration of the agrofuel sector (Golub et al., 2008). The second one consists in coupling partial equilibrium or computable general equilibrium (CGE) models with spatially explicit models including knowledge on biophysical processes (see e.g. KLUM and GTAP; Ronneberger et al., 2009 or GCAM and AGLU; Brenkert et al., 2003).

In contrast with the traditional approach, these two methods demonstrate a strong multidisciplinary orientation. To provide a consistent vision of the socio-biospheric system, they rely either on elasticity parameters estimated on sample data by econometric methods (as e.g. implemented in MIRAGE, Decreux and Valin, 2007), or on an explicit description of the agricultural sector both in economic and biophysical terms. In van Meijl et al. (2006), demand for land and intensification from the GTAP general equilibrium model is used in the IMAGE model to determine changes in land yield and feed efficiency rates. Two partial equilibrium models of the agricultural sector, MAgPIE (LotzeCampen et al., 2008) and GLOBIOM (Havlík et al., 2011), take into account economic constraints through a cell-based cost minimisation, and are coupled with a dynamic vegetation model with explicit crop functional types. MAgPIE is coupled with the Lund-Postdam-Jena dynamic global vegetation model for managed Land (LPJmL, Bondeau et al.,
2007), while GLOBIOM uses the EPIC model (Izaurralde et al., 2006), allowing for a full representation of the dynamic processes linking climate and soil conditions, water availability, and plant growth at a detailed geographic scale over the entire world.

Within those evolutions, this paper provides a bioeconomic modelling framework which ensures at the global level consistency between economic behaviours and spatial biophysical constraints in the manner of MAgPIE or GLOBIOM. This model, called Nexus Land-Use, is designed to represent the processes of agricultural intensification, which are viewed as a key factor to bridge the conflicts on land-use. The Nexus Land-Use has some common features with GLOBIOM and MAgPIE, but in contrast with these two models, crops are aggregated as a representative product in calories and intensification for the representative crop is a non-linear function of chemical inputs.

The principle of the model is simple. An external yearly demand of plant and animal calories in quantity must be met by adequate supply. To do so, the yield of crop plants can be increased by fertiliser and pesticide additions, up to a limit defined as potential yield. The demand of animal calories is converted into different types of feed, mainly: crops, grass from permanent pasture and fodder crops. The model calculates explicitly the crop yield and pastures and cropland areas, so as to minimise farmers' production costs. The evolution of these areas is determined by modelling a Ricardian production frontier (Ricardo, 1817) between an extensive system (extensive grazing only) located on lands with the lowest potential yields and an intensive system (fertilised grasslands and croplands).

In the version 1.0 of the model described in this paper, land is split into 12 regions of the globe (Fig. 2, Table 1), and 6 land-use types: forests, 3 types of croplands and 2 types of pastures. The model external drivers are the calorie 
Table 1. Main input data for each region of the model at the base year 2001. Cropland and pasture areas are from Ramankutty et al. (2008) and forests areas from Poulter et al. (2011), other data are from Agribiom (Dorin, 2011). Population is in millions. Diet is calorie consumption in kcal per capita and per day followed by the fraction of animal products in brackets. Consumption for seed, waste at the farm level and other consumption of food crops such as lubricants and cosmetics in kcal cap ${ }^{-1}$ day $^{-1}$. Net imports of food crops and animal products in $\mathrm{kcal} \mathrm{cap}^{-1} \mathrm{day}^{-1}$. Food crops used as feed in $\mathrm{kcal} \mathrm{cap}^{-1}$ day $^{-1}$ (Sect. 5.4). Areas are in Mha. $1 \mathrm{kcal}=4.1868 \mathrm{~kJ}$.

\begin{tabular}{|c|c|c|c|c|c|c|c|c|c|}
\hline \multirow[t]{2}{*}{ Regions } & \multirow[t]{2}{*}{ Population } & \multirow[t]{2}{*}{ Diet } & \multirow{2}{*}{$\begin{array}{r}\text { Seed, waste } \\
\text { Other }\end{array}$} & \multicolumn{2}{|c|}{ Net imports of food } & \multirow{2}{*}{$\begin{array}{l}\text { Food crops } \\
\text { for animals }\end{array}$} & \multicolumn{3}{|c|}{ Area } \\
\hline & & & & Crops & Animal & & Cropland & Pasture & Forest \\
\hline USA & 311 & $4105(30 \%)$ & 861 & -3344 & -135 & 6939 & 180 & 224 & 334 \\
\hline Canada & 31 & $4167(30 \%)$ & 1424 & -7408 & -435 & 9174 & 42 & 19 & 458 \\
\hline Europe & 585 & $3875(30 \%)$ & 1053 & 930 & -52 & 4248 & 154 & 77 & 220 \\
\hline OECD Pacific & 197 & $2988(20 \%)$ & 364 & 1919 & -165 & 2208 & 34 & 277 & 276 \\
\hline FSU & 280 & $3101(20 \%)$ & 1010 & 138 & 62 & 2515 & 205 & 332 & 894 \\
\hline China & 1284 & $3005(17 \%)$ & 598 & 254 & 19 & 1314 & 141 & 272 & 209 \\
\hline India & 1060 & $2310(8 \%)$ & 284 & 34 & -2 & 212 & 169 & 11 & 65 \\
\hline Brazil & 177 & $3168(22 \%)$ & 1146 & -2161 & -72 & 2674 & 50 & 176 & 526 \\
\hline Middle East & 146 & $3076(12 \%)$ & 488 & 2550 & 74 & 1626 & 29 & 88 & 36 \\
\hline Africa & 826 & $2510(6 \%)$ & 438 & 636 & 26 & 458 & 213 & 764 & 788 \\
\hline Rest of Asia & 884 & $2430(8 \%)$ & 502 & -379 & 17 & 500 & 154 & 130 & 359 \\
\hline Rest of LAM & 324 & $3067(19 \%)$ & 782 & -721 & 94 & 1623 & 108 & 325 & 553 \\
\hline World & 6106 & $2893(16 \%)$ & 603 & - & - & 1644 & 1477 & 2694 & 4721 \\
\hline
\end{tabular}

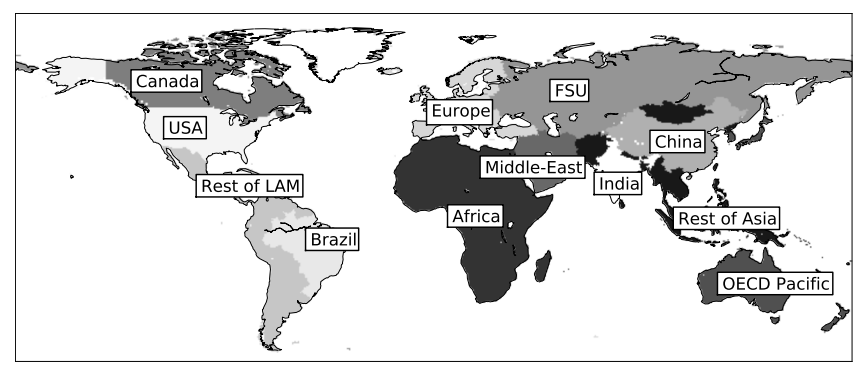

Fig. 2. Nexus Land-Use regions. OECD Pacific includes Australia, New Zealand, Japan and South Korea. FSU stands for former Soviet Union and Rest of LAM for Rest of Latin America.

consumption per capita, the share of animal products in food consumption, agrofuel consumption and evolution of forest areas (Fig. 1). Population and an index of fertiliser and pesticide prices are forced by external scenarios. Some of these variables could be endogenously driven in future versions of the model.

The Nexus Land-Use can be used for many purposes, especially: (i) testing the impact of scenarios regarding diverse variables (food diets/preferences, demand for agrofuel and other non-food agricultural products, prices of fossil energy and agricultural chemical inputs, forest policies, trade policies, etc.) on agricultural land-use change across the world and their consequences (on food prices, regional consumption of agricultural inputs, regional trade balances, etc.) and, (ii) assessing climate policies through a linkage with the general equilibrium model Imaclim-R (Crassous et al., 2006). This paper focuses only on the core structure of the
Nexus Land-Use without describing its future interactions with Imaclim-R (food demand, GHG emissions, etc.).

The next section details our modelling strategy and the scope of analysis. Section three describes the biophysical features of the Nexus Land-Use model. The fourth section details economical principles governing land-use changes and their parametrisations. The fifth section gives some insights on the calibration methodology. In section six, sensitivity of the area of extensive pastures to energy price and deforestation is shown. In the last section, the main hypotheses of the model are discussed.

\section{Scope and principles of the model}

\subsection{Modelling strategy}

The suitability of land for a specific agricultural use depends on its capacity to produce biomass for agriculture, which is itself determined by a large set of biophysical parameters related to soil and climate characteristics. The way farmers make use of these biophysical conditions through agronomic practices is largely driven by the socio-economic environment (evolutions of inputs or outputs prices, regulations, etc.). Although it is difficult to capture all the complex mechanisms governing farmer decisions, economic theories provide some valuable tools to account for them. They generally rely on the assumptions that agents are rational and manage their production system so as to maximise profit. This is equivalent with a cost minimisation in the agricultural sector while meeting a prescribed food demand. 
In this context, the objective of the Nexus Land-Use is to combine these two dimensions - biophysics and economics - in a single coherent modelling framework. First, the representation of the production system is chosen to account for biophysical features as well as agronomic practices. This representation relies on three main components: (i) a detailed representation of the livestock production system based on the Bouwman et al. (2005) model; (ii) potential crop yields from the Lund-Postdam-Jena dynamic global vegetation model for managed Land (LPJmL, Bondeau et al., 2007); and, (iii) a biomass production function inspired by the crop yield response function to inputs (such as nitrogen fertilisers) asymptoting toward the potential yield.

Such a modelling strategy implies that among the four main production factors of the agricultural sector, land and chemical inputs with embodied energy receive particular attention while labour and capital are more roughly modelled. As a consequence, the Nexus Land-Use is better suited to deal with land-use and energy-related issues, including or not including the effect of carbon pricing than, for example, sketching the consequences of agricultural intensification on the labour markets. Irrigation is incorporated into the model through the differentiation of potential yields on rainfed and irrigated lands (see Sect. 3.1).

The economic principles governing farmer decisions are mostly inspired from the Ricardian rent theory (Ricardo, 1817). Following this theory, we consider that the poorer lands are the last to be cultivated. In the Nexus Land-Use modelling framework, the Ricardian frontier is represented as a separation between an intensive system, composed of a mosaic of crops and pastures, and an extensive system, exclusively composed of pastures, the former progressively expanding into the latter as the pressure on land rises. Hence, unlike the original Ricardian vision in which the agricultural system reacts to a growing pressure on land by expanding the size of arable lands over natural ecosystems, adjustments result from reallocations inside the boundaries of the system between intensive and extensive agriculture. This vision is consistent with the report made by Bouwman et al. (2005) that "most of the increase in meat and milk production during the past three decades has been achieved by increasing the production in mixed and industrial production systems and much less so in pastoral systems. Despite the fast increase of ruminant production by $40 \%$ in the $1970-1995$ period, the global area of grassland has increased by only $4 \%$ ".

In the modelling approach presented here, deforestation is not derived from economic trade-offs, and is forced by exogenous scenarios. We actually consider, following Scouvart and Lambin (2006), that the use of forest areas could be increasingly regulated, and that their evolution could subsequently result more from political decisions than from economic ones. With the view to exploring different pathways, this assumption could be relaxed in future development of the model.

\subsection{Modelling architecture}

At the base year, a representative potential yield is computed on a $0.5^{\circ} \times 0.5^{\circ}$ grid from the potential yields given by the vegetation model LPJmL for 11 crop functional types (CFT). Land classes grouping together grid points with the same potential yield are set up. Yield in each land class is determined by a function of chemical inputs, such as fertilisers and pesticides. This function asymptotes toward the potential yield and is characterised by decreasing returns. In each land class, consumption of chemical inputs and associated yield are determined by cost minimisation.

Following Bouwman et al. (2005), the livestock production system is divided into an extensive and an intensive system. The extensive system produces only ruminants that are fed by grazing. The intensive system includes ruminants and monogastrics (non-grazing animals). Here, ruminants are fed by a mix of grass, food crops, residues, fodder and other roughages. In both systems, grass comes from permanent pastures according to the Food and Agriculture Organisation (FAO) definition and can be grazed or cut for hay. Two types of permanent pastures are distinguished - intensive and extensive - according to the system to which they provide grass. Monogastric animals are fed with food crops, residues and fodder and animal products. Croplands are assumed to be exclusively located on the most productive lands, as well as pastures of the intensive production system. Fodder for monogastric and intensive ruminant is grown on cropland. Conversely, the extensive pastures are located on the least productive lands. This split of agricultural land does not completely fit with the data since a sizeable share of extensive pastures are located today on high-yield land classes. Therefore, we consider an additional category of extensive pastures, which is called residual pastures.

Each type of land-use - forest, cropland, intensive, extensive and residual pastures - is distributed among the land classes, giving for a land class of potential yield $j$ the area fractions $f_{j}^{\text {Forest }}, f_{j}^{\text {crop }}, f_{j}^{\text {Pint }}, f_{j}^{\text {Pext }}$ and $f_{j}^{\text {Pres }}$. These variables are regional as are all variables of the model except for the world calorie price.

At each time step, Nexus Land-Use calculates a global supply/demand balance from exogenous calorie consumption of food crops for agrofuel $D_{\text {agrofuel }}^{\text {fc }}$, plant food (food crops for humans) $D_{\mathrm{h}}^{\mathrm{fc}}$, ruminant $D_{\mathrm{h}}^{\mathrm{r}}$ and monogastric products $D_{\mathrm{h}}^{\mathrm{m}}$. The total land supply for agriculture - excluding croplands not represented in LPJmL $-S_{\text {surf }}$ is deduced from the exogenously set annual evolution of the forest area. The price of fertilisers and pesticides is derived from the energy prices trajectories computed by the Imaclim-R model.

Given this forcing, the agricultural sector, with one representative agent per land class, is supposed to minimise its production costs by optimising the consumption of fertilisers and pesticides, triggering subsequent variations of crop yield, and/or by modifying the repartition between intensive and 
extensive livestock production systems. The hypothesis of a representative agent, however, amounts to neglecting the differences between different farms and different situations as long as they are characterised by the same potential yield in a given region. The difference between farm types, especially farms of different sizes, however, is not very problematic, as long run economies of scale in terms of land-use are small (Chavas, 2008). Regions can trade food crops with each other $\left(\operatorname{Exp}^{\mathrm{fc}} / \mathrm{Imp}{ }^{\mathrm{fc}}\right.$, with $\operatorname{Exp}=$ export and Imp = import $)$ as well as ruminant products $\left(\operatorname{Exp}^{\mathrm{r}} / \mathrm{Imp}^{\mathrm{r}}\right)$ on the basis of relative prices and taking into account food sovereignty and market imperfections (the trade of monogastric products $-\operatorname{Exp}^{\mathrm{m}}$, Imp $^{\mathrm{m}}-$ is held constant).

The cost production is minimised in each region under the constraint of a global supply demand balance of ruminant (Eqs. 1-3) and plant food calories (Eqs. 4-7). Demand for agricultural land $D_{\text {surf }}$, which includes croplands and pastures, resulting from this equilibrium must be equal to the land supply $S_{\text {surf }}$ (Eq. 8):

$$
\begin{aligned}
& Q_{\mathrm{r}}=\left(D_{\mathrm{h}}^{\mathrm{r}}+\operatorname{Exp}^{\mathrm{r}}-\operatorname{Imp}^{\mathrm{r}}\right)\left(1+\omega_{\text {swof }}^{\mathrm{r}}\right) \\
& Q_{\mathrm{r}, \text { ext }}=D_{\text {surf }} \rho_{\text {past }}^{\mathrm{r}, \mathrm{ext}} \int\left(f_{j}^{\text {Pext }}+f_{j}^{\text {Pres }}\right) d j \\
& Q_{\mathrm{r}, \text { int }}=Q_{\mathrm{r}}-Q_{\mathrm{r}, \text { ext }} \\
& D_{\mathrm{r}, \text { int }}^{\mathrm{fc}}=Q_{\mathrm{r}, \text { int }} \beta_{\mathrm{r}, \text { int }} \phi_{\mathrm{r}, \text { int }}^{\mathrm{fc}} \\
& D_{\mathrm{m}}^{\mathrm{fc}}=\left(D_{\mathrm{h}}^{\mathrm{m}}+\operatorname{Exp}^{\mathrm{m}}-\operatorname{Imp}^{\mathrm{m}}\right)\left(1+\omega_{\mathrm{swof}}^{\mathrm{m}}\right) \beta_{\mathrm{m}} \phi_{\mathrm{m}}^{\mathrm{fc}} \\
& D^{\mathrm{fc}}=D_{\mathrm{h}}^{\mathrm{fc}}+D_{\mathrm{m}}^{\mathrm{fc}}+D_{\mathrm{r}, \text { int }}^{\mathrm{fc}}+D_{\text {agrofuel }}^{\mathrm{fc}}+\operatorname{Exp}^{\mathrm{fc}}-\operatorname{Imp}^{\mathrm{fc}} \\
& Q_{\text {other crop }}^{\mathrm{fc}}+D_{\text {surf }} \int f_{j}^{\mathrm{crop}} \rho_{j} d j=D^{\mathrm{fc}}\left(1+\omega_{\text {swo }}^{\mathrm{fc}}\right) \\
& S_{\text {surf }}=D_{\text {surf }} .
\end{aligned}
$$

The ruminant production $Q_{\mathrm{r}}$ is deduced from Eq. (1). Seed (s), waste (w) at the farm level and other uses (o) are added by using coefficients $\omega_{\text {swo }}^{\text {fc }}$ for food crops, $\omega_{\text {swof }}^{\mathrm{r}}$ for ruminants and $\omega_{\text {swof }}^{\mathrm{m}}$ for monogastrics (see Sect. 5.1, $f$ standing for feed use of animal products). Following our representation of the ruminant production system, $Q_{\mathrm{r}}$ results either from the extensive ruminant production system, yielding $Q_{\text {rext }}$ (Eq. 2), or from the intensive one, yielding $Q_{\text {r,int }}$ (Eq. 3). Production of ruminant meat and milk in the extensive system is calculated by applying the yield $\rho_{\text {past }}^{\text {reext }}$ to the areas of extensive and residual pastures (Eq. 2). The demand for feed to produce ruminant $D_{\mathrm{r}, \mathrm{int}}^{\mathrm{fc}}$ or monogastric $D_{\mathrm{m}}^{\mathrm{fc}}$ calories is deduced from Eqs. (4) and (5) using the conversion factors $\beta_{\mathrm{r} \text {,int }}$ and $\beta_{\mathrm{m}}$ and the feed composition factor $\phi_{\mathrm{r}, \text { int }}^{\mathrm{fc}}$ and $\phi_{\mathrm{m}}^{\mathrm{fc}}$ (see Sect. 3.3). Equation (6) gives the composition of the demand for food crops between food use $\left(D_{\mathrm{h}}^{\mathrm{fc}}\right)$, feed use $\left(D_{\mathrm{r} \text {,int }}^{\mathrm{fc}}\right.$ and $D_{\mathrm{m}}^{\mathrm{fc}}$ ), agrofuel $\left(D_{\text {agrofuel }}^{\mathrm{fc}}\right)$ and trade. Equation (7) corresponds to the supply/demand equilibrium for food crops. A part of the cropland areas, yielding $Q_{\text {other crop }}^{\mathrm{fc}}$, is not modelled by the vegetation model LPJmL. Its evolution is forced by an external scenario. The reader will find descriptions and units of main notations in Table 9.

\subsection{Biomass categories}

Only edible biomass is accounted for, excluding fibres, rubber, tobacco, etc. All quantities are measured according to their energy content, and expressed in kilocalories (kcal), this unit being commonly used for nutrition $(1 \mathrm{kcal}=4.1868 \mathrm{~kJ})$. This measure allows to deal with different types of biomass for human or animal consumption but it has some drawbacks. First, calories from different crops do not have the same economical value, e.g. the price of a cereal calorie has less value than a coffee calorie. From a nutritional point of view, a sufficient quantity of calories does not always correspond to a sufficient quantity of macronutriments (protein, lipids and carbohydrates) or micronutriments (vitamins, minerals).

Four categories of agricultural products are represented (Fig. 3): first generation agrofuel, plant food for human consumption, monogastric animals and ruminant animals (producing meat and milk from cattle, sheep, goats and buffalo). Other uses of edible crop biomass correspond to non-food production, such as lubricants or cosmetics (not represented in Fig. 3, see Sect. 5.1 for more details). Demand for each of these four categories is forced by exogenous scenarios (Fig. 1).

Agrofuels are represented separately and will be the subject of a future publication. Plant food for human consumption is directly assigned to food use. Animal production is modelled following Bouwman et al. (2005). According to this representation, feed for ruminants and monogastric animals are divided into five categories: (i) grass, including grazing, hay and silage grass; (ii) food crops and by-products (such as cakes); (iii) crop residues and fodder crops, including straw and bran; (iv) animal products, including whey, bone and fish meal; and, (v) scavenging, including road-side grazing, household wastes, feedstuffs from backyard farming, etc. Contrary to grass and food crops, the last two categories are not assigned to specific land-uses. The special case of the residues and fodder category is explained in Sect. 3.3.

The balance of supply and demand of food crop products is established on the basis of data from the global database Agribiom (Dorin, 2011). This database provides, for each country, the biomass balances in kilocalories based on the FAO annual country-level supply-utilisation accounts, ensuring consistency among the annual flows of edible biomass which are produced, traded, and consumed. In Nexus LandUse, food crop production is modelled on the basis of crop yields computed by the vegetation model LPJmL, explicitly accounting for biophysical constraints (see Sect. 3.1).

At base year 2001, crops modelled by LPJmL cover 749 Mha globally, representing $51 \%$ of the global cropland area inventoried by Ramankutty et al. (2008). Yields modelled by LPJmL are calibrated on FAO data (see Sect. 3.1). The resulting production accounts for $75 \%$ of global food crops calorie production given by Agribiom (Table 2). The production covered by LPJmL and corresponding cropland areas are called dynamic. The remaining food crop 


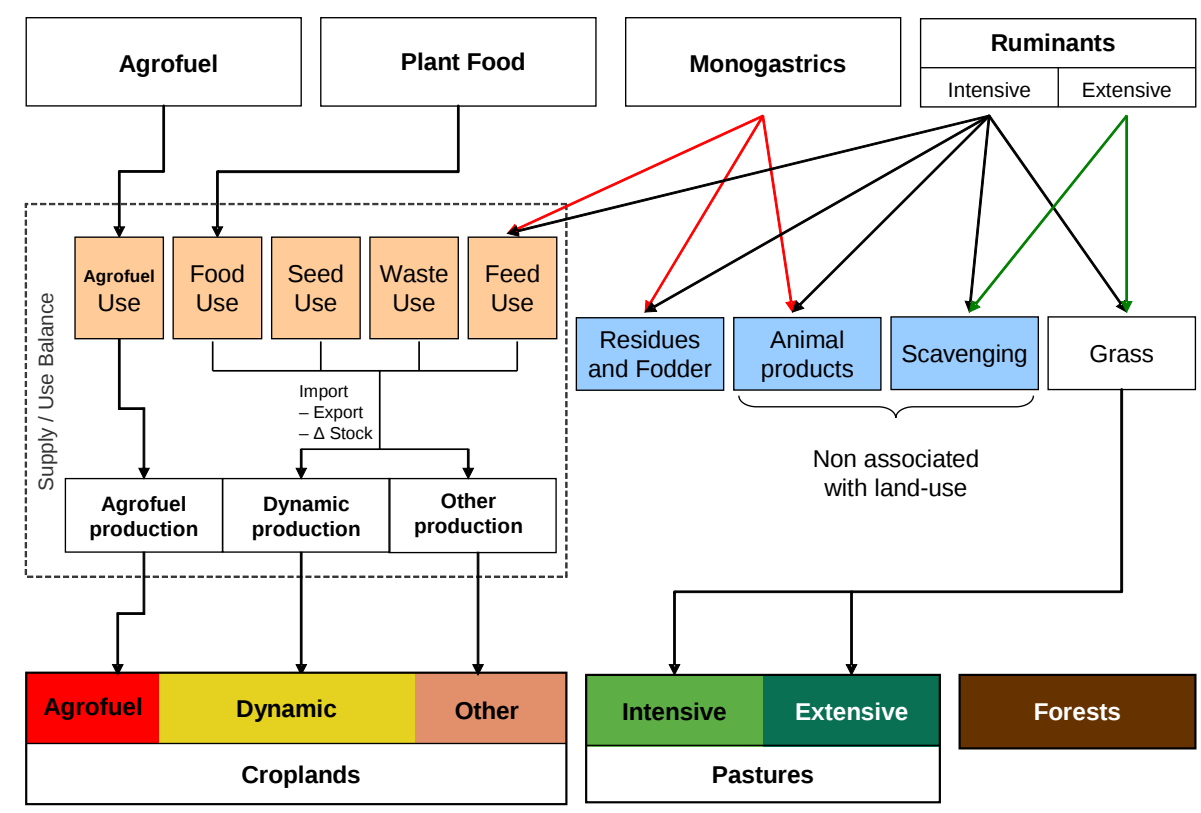

Fig. 3. Links between food and agrofuel demand and land-use.

Table 2. Mean of food crop production over the period 1999-2003 from Agribiom and LPJmL production according to actual yields and annual fractional coverage per grid cell CFT around the year 2000 from Fader et al. (2010). Ramankutty cropland area in the year 2000 and LPJmL cropland area around the year 2000. LPJmL cropland area and production are referred to as dynamic in the paper. 1 Pkcal $=4187 \mathrm{PJ}$.

\begin{tabular}{lccccc}
\hline \multirow{2}{*}{ Region } & \multicolumn{2}{c}{ Crop production (Pkcal) } & & \multicolumn{2}{c}{ Croplands (Mha) } \\
\cline { 2 - 3 } \cline { 5 - 6 } \cline { 5 - 6 } & Agribiom & LPJmL & & Ramankutty & LPJmL \\
\hline USA & 1.61 & $1.60(99 \%)$ & & 180.1 & $94.5(52 \%)$ \\
Canada & 0.23 & $0.20(89 \%)$ & & 41.5 & $23.8(57 \%)$ \\
Europe & 1.52 & $1.32(87 \%)$ & & 153.4 & $86.0(56 \%)$ \\
OECD Pacific & 0.24 & $0.16(65 \%)$ & & 33.8 & $19.5(58 \%)$ \\
FSU & 0.61 & $0.54(88 \%)$ & & 203.2 & $79.2(39 \%)$ \\
China & 1.87 & $1.32(71 \%)$ & & 140.8 & $87.0(62 \%)$ \\
India & 1.06 & $0.72(68 \%)$ & & 168.6 & $108.5(64 \%)$ \\
Brazil & 0.53 & $0.31(58 \%)$ & & 49.7 & $28.4(57 \%)$ \\
Middle East & 0.13 & $0.09(72 \%)$ & & 29.0 & $13.7(47 \%)$ \\
Africa & 0.83 & $0.46(56 \%)$ & & 212.3 & $96.5(45 \%)$ \\
Rest of Asia & 1.24 & $0.67(54 \%)$ & & 153.3 & $66.1(43 \%)$ \\
Rest of LAM & 0.67 & $0.45(67 \%)$ & & 107.0 & $45.7(43 \%)$ \\
\hline World & 10.52 & $7.84(75 \%)$ & & 1472.7 & $748.8(51 \%)$ \\
\hline
\end{tabular}

production is called other (see Fig. 3) and essentially comprises sugar cane, palm oil, some roots and tubers, fruits and other vegetables. The cropland category other is not only dedicated to grow crops not modelled in LPJmL, but also includes fallows, cultivated area for non-food crops (fibres, rubber, tobacco, ...) and fodder crops except those represented in LPJmL (therefore excluding maize, rye grass and sorghum). Evolutions of other productions and other cropland areas are forced by external scenarios. Areas of permanent pastures are taken from Ramankutty et al. (2008) and forests areas from Poulter et al. (2011). On grid points where the sum of forest, pasture and cropland fractions exceed $100 \%$, forest fractions were reduced to match $100 \%$. We consider that Poulter et al. (2011) map is less relevant because it is only based on satellite data, while Ramankutty et al. (2008) maps include national inventories. Consequently, the forest map was reduced by $325 \mathrm{Mha}$ on 5064 Mha. The forest category includes managed and unmanaged forests. As the silvicultural sector is not modelled, no distinction between the two forest types is made. Other non-agricultural lands (deserts, ice, wetlands and built areas) are considered constant. 
Except for three feed categories (residues and fodder, animal products and scavenging), each feedstock category corresponds to a given land-use. Production of fodder crop is an important land-use, but we consider that we have not enough data to incorporate changes in fodder crop yield or areas in the model.

The modelling of pasture areas is related to ruminant production. In the Nexus Land-Use model, ruminant products are assumed to stem either from an intensive system or from an extensive one (see Sect. 3.3). In the former system, ruminants are fed with the five types of feed mentioned above, while in the latter system, they are fed exclusively by scavenging and grazing on extensive pastures. Each system is associated with its specific pastures (intensive or extensive) and with the amount of grass that is consumed per hectare. Finally, the forced evolution of forest areas determines the supply for croplands and pastures.

\subsection{Model resolution}

The model is solved in several steps. At each time step, the exogenous drivers (see Fig. 1) are injected into the model. Changes in agricultural areas (including pastures and croplands) are deduced from exogenous evolutions of forest areas, neglecting phenomenons such as extension of urban areas. That is to say, the sum of all land-use categories is supposed to be constant throughout the projection period. Changes in agricultural areas are not distributed uniformly over land classes. Deforested areas are allocated to the agricultural surface pool proportionally to the size of forest area present in each land class. Conversely, afforested areas are taken from the forest distribution in proportion to the size of agricultural area in each land class.

Then, the cost minimisation program is solved each year for each region with respect to the supply demand equilibrium (Eqs. 1 to 8), providing the actual crop yield $\rho_{j}$ and the repartition between intensive and extensive livestock production systems. As the pressure on land grows, in response to - all other things being equal - a rise of energy price and/or food crops domestic demand and/or a reduction of agricultural area, the actual crop yield is increased by higher inputs of fertilisers and pesticides and the intensive livestock production expands towards less fertile land classes. Extensive pastures become thus converted into dynamic croplands, intensive and residual pastures, according to their average area fraction on land classes of the intensive system (see Fig. 11).

The area of intensive pastures is subject to the additional constraint of meeting the grass demand from ruminants in the intensive system:

$$
\sum_{j} f_{j}^{\text {Pint }} D_{\text {surf }} \rho_{\text {past,int }}^{\text {grass }}=Q_{\mathrm{r}, \text { int }} \beta_{\mathrm{r}, \text { int }} \phi_{\mathrm{r}, \text { int }}^{\text {grass }} .
$$

When intensive pasture area needs to be increased, land is taken from residual pastures if possible. Otherwise, land is taken from or allocated to to dynamic cropland.
Imports and exports, consumption of pesticides and fertilisers, calorie price and land price are simultaneously computed within the cost minimisation program as explained in Sects. 4.3 and 4.4.

Residual pastures are considered to be an inefficient use of land, therefore its area in each land class gets reduced as soon as the pressure on land is higher than its reference level for the year 2001. The conversion speed is linearly related with the pressure on land.

\section{Modelling agricultural intensification and biophysical constraints}

\subsection{Land area classes of potential yields}

\subsubsection{Potential yields computation in LPJmL}

To represent biophysical constraints affecting cultivation, yield in each region of the Nexus Land-Use is parametrised on potential crop yields, and calibrated on actual crop yields. Both values are calculated by the LPJmL vegetation model: "This model simulates biophysical and biogeochemical processes impacting productivity of the most important crops worldwide using a concept of crop functional types (CFTs). [...] CFTs are generalized and climatically adapted plant prototypes designed to capture the most widespread types of agricultural plant traits" (Bondeau et al., 2007).

LPJmL describes crop production with 11 CFTs on a $0.5^{\circ} \times 0.5^{\circ}$ grid representing most of the cereals $(4 \mathrm{CFT})$, oil seed crops (4 CFT), pulses, sugar beet and cassava with irrigated and rainfed variants (Table 3). Crops not included in LPJmL CFTs (e.g. sugar cane, oil palm, fruits and vegetables, etc.) are referred to as other crops. Climatic potential yields $y_{\mathrm{CFT}, l}^{\max }$ in tons of fresh matter per hectare and per year (tons FM ha ${ }^{-1} \mathrm{yr}^{-1}$ ) are computed by LPJmL for each of the 11 CFTs with irrigated and rainfed variants, at each grid point of global land area (1 subscript), by setting management intensity parameters in LPJmL such that crop yield is maximized locally. Climatic potential yields are taken as a mean of five LPJmL simulation years between 1999 and 2003 in order to minimise the climatic bias due to interannual variability.

Management intensity is approximated in LPJmL via 3 parameters: (i) LAImax, the maximum leaf area index potentially achievable by the crops, representing general plant performance (fertilisation, pest-control), (ii) $\alpha a$, a scaling factor between leaf-level photosynthesis and stand-level photosynthesis, which accounts for planting density and homogeneity of crop fields, and (iii) the harvest index HI, which determines the partitioning of accumulated biomass to the storage organs. These three parameters are assumed to be interlinked, i.e. high-yielding varieties (large HI) are used in intensively managed crop stands (Gosme et al., 2010). For details see Fader et al. (2010). 
Table 3. FAO and MIRCA2000 (Portmann et al., 2010) aggregates corresponding to LPJmL CFTs. Calorie content cal ${ }_{\text {CFT in }}$ Mkcal tons $^{-1}$ of fresh matter from Agribiom, followed by the share of each CFT in global cropland area in percent (1493 Mha in 2000, Ramankutty et al., 2008) and in global food crops production (mean over the 1999-2003 period: 10.5 Pkcal, Agribiom).

\begin{tabular}{|c|c|c|c|c|c|}
\hline FAO crops & MIRCA2000 crops & LPJmL CFTs & $\mathrm{cal}_{\mathrm{CFT}}$ & $\%$ Area & $\%$ Production \\
\hline $\begin{array}{l}\text { Wheat } \\
\text { Barley } \\
\text { Rye } \\
\text { Rye grass for forage } \\
\text { and silage }\end{array}$ & $\begin{array}{c}\text { wheat } \\
\text { barley } \\
\text { rye }\end{array}$ & wheat & 3.34 & 17.0 & 22.1 \\
\hline Rice & rice & rice & 3.6 & 6.7 & 13.6 \\
\hline $\begin{array}{l}\text { Green corn (maize) } \\
\text { Maize } \\
\text { Maize for forage } \\
\text { and silage }\end{array}$ & maize & maize & 3.56 & 9.2 & 21.8 \\
\hline $\begin{array}{l}\text { Millet } \\
\text { Sorghum } \\
\text { Sorghum for forage } \\
\text { and silage }\end{array}$ & $\begin{array}{c}\text { millet } \\
\text { sorghum }\end{array}$ & millet & 3.4 & 4.7 & 1.9 \\
\hline $\begin{array}{l}\text { Beans, dry } \\
\text { Beans, green } \\
\text { Broad beans, dry } \\
\text { Broad beans, green } \\
\text { Chick peas } \\
\text { Cow peas, dry } \\
\text { Lentils } \\
\text { Lupins } \\
\text { Peas, dry } \\
\text { Peas, green } \\
\text { Pulses, other }\end{array}$ & pulses & field pea & 3.46 & 4.1 & 2.0 \\
\hline Sugar beets & sugar beets & sugar beets & 0.7 & 0.4 & 1.5 \\
\hline Cassava & cassava & cassava & 1.09 & 1.3 & 2.1 \\
\hline Sunflower seed & sunflower & sunflower & 5.7 & 1.3 & 1.3 \\
\hline Soybeans & soybeans & soybeans & 4.16 & 4.6 & 6.1 \\
\hline Groundnuts & $\begin{array}{l}\text { groundnuts } \\
\text { peanuts }\end{array}$ & groundnuts & 5.67 & 1.3 & 1.6 \\
\hline Rapeseed & $\begin{array}{l}\text { rapeseed } \\
\text { canola }\end{array}$ & rapeseed & 4.94 & 1.5 & 1.6 \\
\hline
\end{tabular}

\subsubsection{Actual yields computation in LPJmL}

CFT actual yields $y_{\mathrm{CFT}, l}^{\text {actual }}$ in tons $\mathrm{FM} \mathrm{ha}^{-1} \mathrm{yr}^{-1}$ are computed by LPJmL in the following way. First, LPJmL yield is determined, with an arbitrary intensity level of 5 for each grid point and averaged over the 1999-2003 period (intensity level is represented by the parametrisation of LAImax, $\alpha a$ and $\mathrm{HI}$ and ranges from 1 (low) to 7 (high, depending on the CFT)). Then, for each CFT and each country, a scaling coefficient is computed, such that the mean country yield matches the FAO yield over the same period. This mean country yield is calculated using annual fractional coverage of each CFT in each grid point around the year $2000 f_{\mathrm{CFT}, l}$ from Portmann et al. (2010). When the scaling coefficient was greater than ten, corresponding yields were set to zero considering that LPJmL failed to model these CTFs in these countries. For some CFTs (rice, maize, soybeans) on certain grid points the scaling on FAO national yield led to actual yields greater than potential ones. This may be due to the fact that the LPJmL version used here does not model multi-cropping (except for rice) while there may be as much as 3 harvests annually in some parts of Asia (Portmann et al., 2010). Moreover, the LPJmL CFTs may have failed to represent the dynamic of 
Table 4. Monogastric feed conversion factor $\beta_{\mathrm{m}}$ ( $\mathrm{kcal}$ of feed/kcal of monogastric product). Share of food crops $\phi_{\mathrm{m}}^{\mathrm{fc}}$ and fodder $\phi_{\mathrm{m}}^{\text {fodder }}$ in feed. Calories of food crop needed to produce one calorie of monogastric meat and eggs $\beta_{\mathrm{m}} \times \phi_{\mathrm{m}}^{\mathrm{fc}}$. Feed conversion factor of ex-

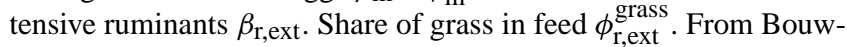
man et al. (2005) and modified as explained in Sect. 5.4

\begin{tabular}{lcccccc}
\hline Regions & $\beta_{\mathrm{m}}$ & $\phi_{\mathrm{m}}^{\mathrm{fc}}$ & $\phi_{\mathrm{m}}^{\text {fodder }}$ & $\beta_{\mathrm{m}} \times \phi_{\mathrm{m}}^{\mathrm{fc}}$ & $\beta_{\mathrm{r}, \mathrm{ext}}$ & $\phi_{\mathrm{r}, \mathrm{ext}}^{\text {grass }}$ \\
\hline USA & 8.1 & 0.84 & 0.16 & 6.8 & 23.77 & 1.00 \\
Canada & 8.3 & 0.84 & 0.16 & 6.9 & 25.56 & 1.00 \\
Europe & 8.7 & 0.71 & 0.28 & 6.2 & 73.11 & 0.95 \\
OECD Pacific & 8.8 & 0.73 & 0.27 & 6.4 & 21.92 & 0.98 \\
FSU & 10.5 & 0.67 & 0.32 & 7.1 & 22.89 & 0.95 \\
China & 9.6 & 0.30 & 0.70 & 2.9 & 31.45 & 0.95 \\
India & 11.0 & 0.59 & 0.41 & 6.5 & 163.89 & 0.50 \\
Brazil & 9.8 & 0.70 & 0.30 & 6.9 & 88.68 & 0.95 \\
Middle East & 10.8 & 0.73 & 0.26 & 7.9 & 51.02 & 0.95 \\
Africa & 10.5 & 0.69 & 0.31 & 7.3 & 98.53 & 0.95 \\
Rest of Asia & 10.0 & 0.30 & 0.70 & 3.0 & 146.03 & 0.58 \\
Rest of LAM & 10.2 & 0.51 & 0.49 & 5.2 & 85.39 & 0.95 \\
\hline
\end{tabular}

the local variety of these crops in these regions. To correct this bias, the potential yield of CFTs was set to actual yield on grid points where the actual yield was higher. This led to the addition of $1 \mathrm{Pkcal}\left(10^{9} \mathrm{Mkcal}\right)$ to the potential production, corresponding to $7 \%$ of the total potential production on current croplands.

\subsubsection{Aggregation of potential and actual yields into land area classes}

One way to model food crop production is to dynamically allocate CFTs on grid points according to their expected production costs. This methodology was used by the land-use model MAgPIE where CFT choices are determined by minimizing total cost of production (Lotze-Campen et al., 2008). A drawback is that only one optimal CFT is then grown in each location. In MAgPIE this drawback is overcome by forcing rotational constraint, that is minimal and maximal shares of CFT groups (pulses, cereals, etc.) within a grid cell. In Nexus Land-Use we use a different methodology in which the potential yields of a fixed mix of CFTs are aggregated to one representative crop.

To this end, potential yields are converted in the Nexus Land-Use into calories with coefficients from Agribiom $\mathrm{cal}_{\mathrm{CFT}}$ (see Table 3). The resulting calorie yields are then combined with the annual fractional coverage of each CFT in each grid cell around the year $2000 f_{\mathrm{CFT}, l}$, separately for irrigated and rainfed areas, and aggregated into one representative potential yield $y_{l}^{\text {max, agg }}$ (in Mkcal ha ${ }^{-1} \mathrm{yr}^{-1}$ ). Fractional coverages are derived from maximal monthly harvested areas of each CFT at $0.5^{\circ}$ resolution from Portmann et al. (2010). In the case of multi-cropping (more than one crop cycle within a year in the same grid point) the fractions of each CFT were adjusted to match the total cropland fraction given by Ramankutty et al. (2008) (see Fader et al., 2010 for details on

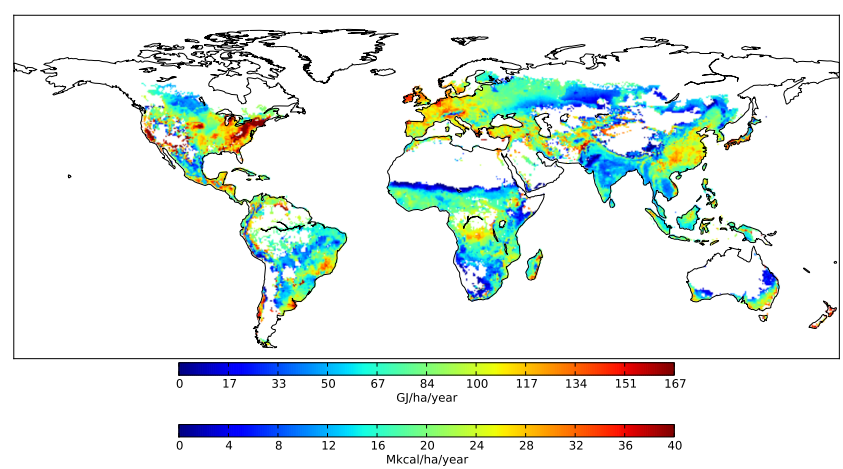

Fig. 4. Representative potential yield of crops modelled in the LPJmL model (dynamic crops), average over the 1999-2003 period.

CFT fractions of cells). These representative potentials yields must be interpreted as the maximum achievable yield on a grid cell assuming the CFT fractional coverage around the year 2000, and not as the maximum achievable yield on a grid cell assuming $100 \%$ coverage by the most productive CFT.

The representative potential yield on grid point $l$ is given by

$y_{l}^{\text {max, agg }}=\frac{\sum_{\mathrm{CFT}} y_{\mathrm{CFT}, l}^{\max } \times f_{\mathrm{CFT}, l} \times \mathrm{cal}_{\mathrm{CFT}}}{\sum_{\mathrm{CFT}} f_{\mathrm{CFT}, l}}$.

It is displayed in Fig. 4. The representative actual yield is computed likewise and its spatial distribution is displayed in Fig. 5. In Nexus Land-Use, grid points where LPJmL crops are grown (dynamic cropland in the following) are aggregated into classes of iso-potential yields. From this aggregation, we define a land class as the sum of grid point area associated with a potential yield value within a specific range. For example, land class 15 includes grid points with a potential yield between 14 and $15 \mathrm{Mkcal} \mathrm{ha}^{-1} \mathrm{yr}^{-1}$ in each region. Given this definition, the area of dynamic croplands $S_{j}^{\text {crop }}$ in the land class $j$ is

$S_{j}^{\text {crop }}=\sum_{l, \tilde{\rho}_{j}^{\max }<y_{l}^{\max , \operatorname{agg}}<\tilde{\rho}_{j+1}^{\max }} S_{l} \times\left(\sum_{\mathrm{CFT}} f_{\mathrm{CFT}, l}\right)$

where $\tilde{\rho}_{j}^{\max }$ are yields values regularly spaced every $1 \mathrm{Mkcal} \mathrm{ha}^{-1} \mathrm{yr}^{-1}$ interval and $S_{l}$ is the surface of the grid point $l$. The potential yield $\rho_{j}^{\max }$ of land class $j$ is the mean of the potential yield in all all grid points belonging to class $j$ :

$\rho_{j}^{\max }=$
$\frac{\sum_{l, \tilde{\rho}_{j}^{\max }<y_{l}^{\max , a g g}}<\tilde{\rho}_{j+1}^{\max } y_{l}^{\max , \operatorname{agg}} \times\left(\sum_{\mathrm{CFT}} f_{\mathrm{CFT}, l}\right) \times S_{l}}{S_{j}^{\text {crop }}}$.

Sixty land classes of potential yields are considered (from 0 to $60 \mathrm{Mkcal} \mathrm{ha}^{-1} \mathrm{yr}^{-1}$ ). Using the same method, actual 


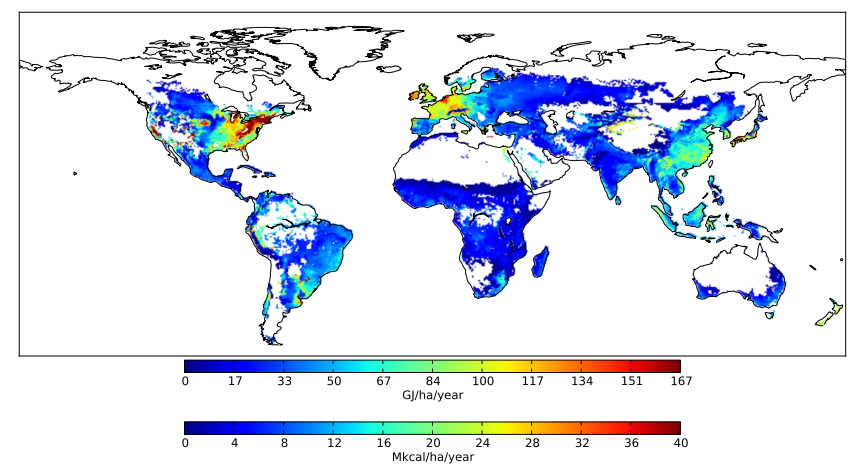

Fig. 5. Representative actual yield of crops modelled in the LPJmL model (dynamic crops), average over the 1999-2003 period.

yields of each land class $\rho_{j}^{\text {actual }}$ are computed. We also calculate a representative potential yield on each grid point in case pasture or forests are converted to cropland (Fig. 7). To this end, an hypothetical annual fractional coverage of each CFT on each grid cell is set to the average distribution of CFTs over each country, assuming that each CFT is equally distributed in each grid cell. Only rainfed potential yields are used assuming there is no irrigation on newly converted croplands. In the same way as $y_{l}^{\text {max, agg }}$, these potential yields are the maximum achievable yields in rainfed conditions considering a crop mix over the cropland area of the grid cell representative of the country's crop mix. This rainfed hypothetical potential yield is used to allocate the area of forest, permanent pastures and other croplands within land classes according to their hypothetical yield if they are converted to dynamic croplands in our simulation (see Sect. 2.3 for more details on dynamic and other croplands). An histogram of areas of all land-use types into land classes is shown on Fig. 12.

In addition to the issue related to potential yields being lower than actual yields handled above, another weakness concerns the value of potential yields that seems to be too low in equatorial regions (India, equatorial Brazil). This may be related to the lack of representation of perennial crops (sugar cane, palm oil), which are the most productive crops in these regions (Figs. 6 and 7).

\subsection{Crop production function}

Factors influencing crop yields are numerous and complex. In Nexus Land-Use, yield in each land class is assumed to be a function of intermediate consumption $\left(\mathrm{IC}_{j}\right)$ from the chemical and mineral sectors, which mainly corresponds to the use of fertilisers, pesticides and mineral enrichments. The focus on chemicals and mineral inputs is driven by the observation that high yields are achieved in systems with high levels of mechanisation or no mechanisation at all. This modelling, however, miss cases where additional labour or capital could improve yields. The yield function, shown on Fig. 8, is defined by an initial slope $\frac{1}{\alpha_{\mathrm{IC}}}-$ the same for the sixteen

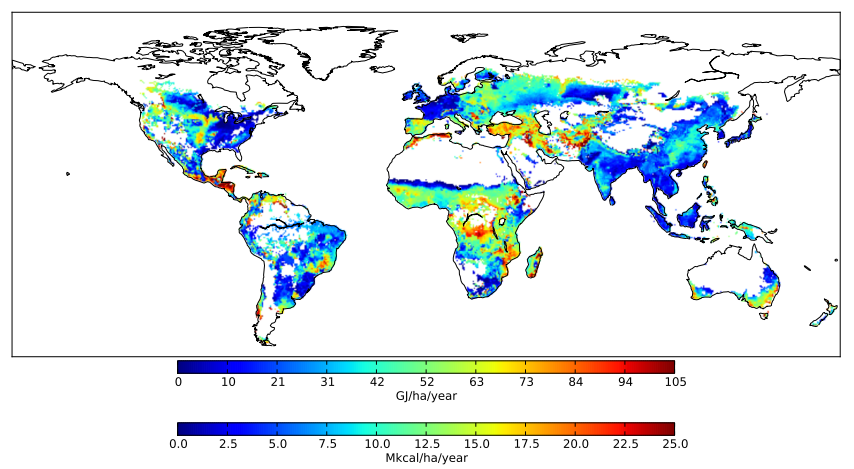

Fig. 6. Difference between potential and actual yield of crops modelled in the LPJmL model (dynamic crops), average over the 19992003 period.

land classes of a region - and an asymptote equal to the potential yield of the land class $\rho_{j}^{\max }$ specified above. $\rho_{j}^{\max }$ corresponds to the yield that could be achieved with unlimited consumption of fertiliser and pesticide inputs, and reflects the saturated response of the crop to photosynthetically active radiation and climate characteristics, as well as agronomic choices such as sowing date. Water use is also accounted for as potential yields are aggregates of rainfed and irrigated crops. The initial slope $\frac{1}{\alpha_{\mathrm{IC}}}$ sets how easily the potential yield can be achieved in each region given the regional socio-economic constraints that may face farmers. The Nexus Land-Use production function can be considered as a form of yield response function to fertiliser application that can be simulated by crop models (Brisson et al., 2003; Godard et al., 2008), and generalised to all types of fertilisers (nitrogen, phosphorus, potassium) and to pesticides. The yield per unit of land is given by

$\rho_{j}\left(\mathrm{IC}_{j}\right)=\rho_{j}^{\max }-\left(\rho_{j}^{\max }-\rho_{j}^{\min }\right) \frac{\alpha_{\mathrm{IC}}\left(\rho_{j}^{\max }-\rho_{j}^{\min }\right)}{\mathrm{IC}_{j}+\alpha_{\mathrm{IC}}\left(\rho_{j}^{\max }-\rho_{j}^{\min }\right)}$

where the minimum yield $\rho_{j}^{\min }$ is the y-intercept, defined as the no-inputs yield. Its value is set to ten percent of the potential yield $\rho_{j}^{\max }$. This choice is somewhat arbitrary but consistent with observations. Indeed, actual yields on the African continent, thought to be close to the minimum yield, are approximately equal to $10 \%$ of the potential yield (see Fig. 9). However, it may lead to an underestimation in temperate regions (T. Doré, personal communication, 2011).

From an economic point of view, Eq. (13) is a production function representing the technical relationship between a quantity of output (yield) and a combination of inputs (fertilisers and pesticides).

\subsection{Livestock production system}

The quantity and composition of feed needed to produce one unit of animal product vary greatly around the world. This is modelled by two parameters: feed conversion factors denoted 


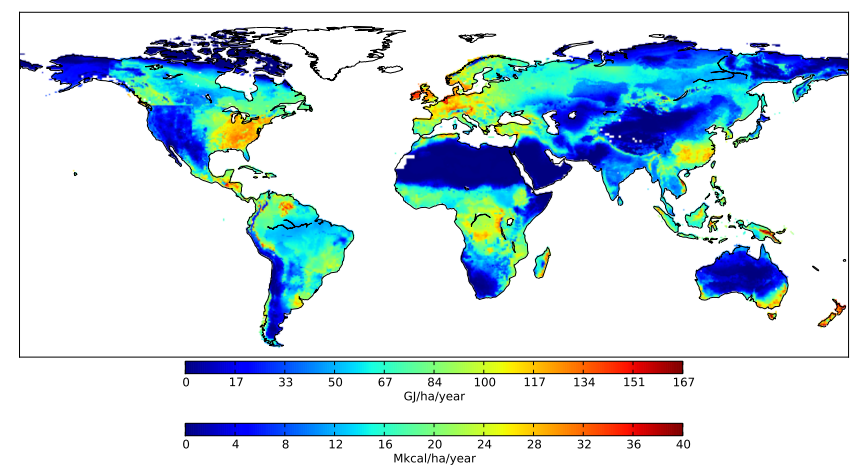

Fig. 7. Potential yield computed with national crop repartitions in rainfed conditions, average over the 1999-2003 period.

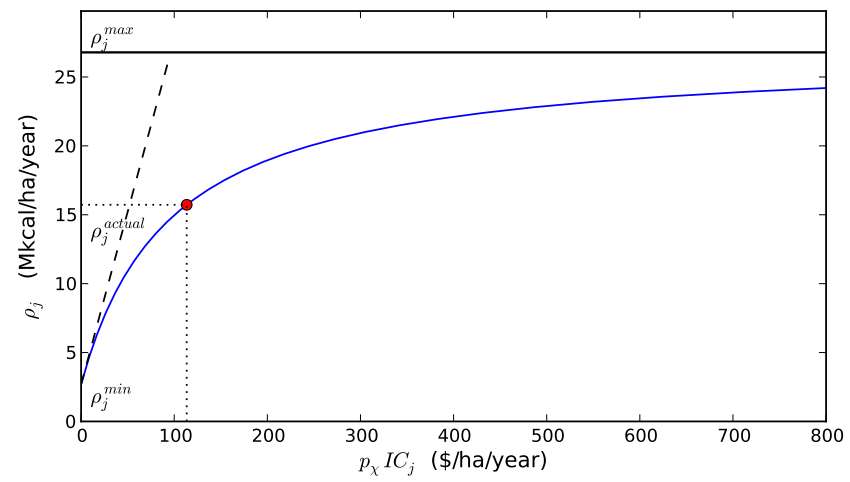

Fig. 8. Yield in a land class as a function of chemical input consumption $\mathrm{IC}_{j} \cdot \rho_{j}^{\max }, \rho_{j}^{\text {actual }}$ and $\rho_{j}^{\min }$ are the potential, actual and minimum yields of the land class $j . p_{\chi}$ is the price index of chemical inputs.

$\beta$, defined as the calories of feed needed to produce one calorie of animal food, and feed composition factors denoted $\phi$, defined as the share of each specific feed category in total feed. Feedstock categories are detailed in Sect. 2.3. $\beta$ and $\phi$ differs amongst animals and regions but also amongst production systems. The feed required by monogastrics and ruminants and its supply by pastures is represented in Fig. 10 except for animal products and scavenging because they are not associated with specific land-use. Feed conversion coefficients are quite different for meat, diary products and eggs. They have been computed considering a constant share of these different products in the ruminant and monogastric production.

Following Bouwman et al. (2005), we consider two farming systems for ruminant production: (i) the extensive system where animals are fed mainly by grazing on extensive pastures and to some extent by scavenging; and (ii) the intensive system or mixed-landless for which animals are fed not only with grass but also with residues and fodder, food crops, animal products and by scavenging. For example, in Europe, ruminants are fed with $13 \%$ of food crops, $33 \%$ of
Table 5. Feed conversion factor of intensive ruminants $\beta_{\text {r,int }}$ (kcal of feed $/ \mathrm{kcal}$ of ruminant product). Share of food crops $\phi_{\mathrm{r}, \text { int }}^{\mathrm{fc}}$, fodder $\phi_{\mathrm{r} \text {,int }}^{\text {fodder }}$ and grass $\phi_{\mathrm{r} \text {,int }}^{\text {grass }}$ in feed. Calories of food crop needed to produce one calorie of intensive ruminant meat and milk $\beta_{\mathrm{r} \text {,int }} \times$ $\phi_{\mathrm{r}, \text { int }}^{\mathrm{fc}}$. From Bouwman et al. (2005) and modified as explained in Sect. 5.4

\begin{tabular}{lccccc}
\hline Regions & $\beta_{\mathrm{r}, \text { int }}$ & $\phi_{\mathrm{r}, \text { int }}^{\mathrm{fc}}$ & $\phi_{\mathrm{r}, \text { int }}^{\text {fodder }}$ & $\phi_{\mathrm{r} \text {,int }}^{\text {grass }}$ & $\beta_{\mathrm{r} \text {,int }} \times \phi_{\mathrm{r}, \text { int }}^{\mathrm{fc}}$ \\
\hline USA & 11.5 & 0.25 & 0.19 & 0.56 & 2.8 \\
Canada & 13.2 & 0.29 & 0.15 & 0.56 & 3.8 \\
Europe & 10.0 & 0.13 & 0.33 & 0.53 & 1.4 \\
OECD Pacific & 13.7 & 0.19 & 0.25 & 0.55 & 2.5 \\
FSU & 12.9 & 0.21 & 0.25 & 0.53 & 2.7 \\
China & 18.4 & 0.10 & 0.28 & 0.57 & 1.9 \\
India & 19.2 & 0.03 & 0.30 & 0.17 & 0.6 \\
Brazil & 38.2 & 0.02 & 0.28 & 0.65 & 0.8 \\
Middle East & 12.3 & 0.29 & 0.34 & 0.30 & 3.6 \\
Africa & 33.5 & 0.08 & 0.28 & 0.59 & 2.7 \\
Rest of Asia & 33.5 & 0.09 & 0.25 & 0.35 & 3.0 \\
Rest of LAM & 31.6 & 0.06 & 0.24 & 0.64 & 2.0 \\
\hline
\end{tabular}

residues and fodder crops and $53 \%$ of grass (see Table 5). Scavenging and animal products account for a small share of the feed consumed by livestock except for scavenging in India - where it is assumed to cover half of ruminant needs (Bouwman et al., 2005).

To separate pasturelands and ruminant heads in each production system, Bouwman et al. (2005) assumed that ruminant heads belonging to the intensive system are located on a grid cell where the fraction of arable land is sufficiently high "to ensure that the production of crops for feeding animals [...] are available at short distance". Indeed, even if some food crops are imported to feed ruminants, Bouwman et al. (2005) suppose that intensive animal farming almost always takes place near croplands. Monogastrics are fed mainly with food crops, residues and fodder. They are also fed with animal products but as for intensive ruminants they account for less than $1 \%$ of the ration.

Representation of fodder crops in land-use models is usually rough. Though, fodder crops in USA, Canada and Europe account for more than $15 \%$ of the total cropland area and up to $21 \%$ in the former Soviet Union (Monfreda et al., 2008). Furthermore, the category residue and fodder constitutes an important share of the intensive ruminant feed ration ranging from $15 \%$ in Canada to $34 \%$ in the Middle East. Land-use for fodder production is not modelled due to an important deficit of data. FAO statistics on fodder production are incomplete, only five crops are inventoried: alfalfa, clover, silage maize, ray-grass and sorghum. Although Monfreda et al. (2008) enhanced data quality by using national inventories, statistics remain unreliable, in particular for Brazil and Asia. Nevertheless, several fodder crops are also included in the LPJmL CFTs (see Table 3), and some areas for fodder production are included in the Ramankutty et al. (2008) cropland map. Therefore, no new cropland land-use 

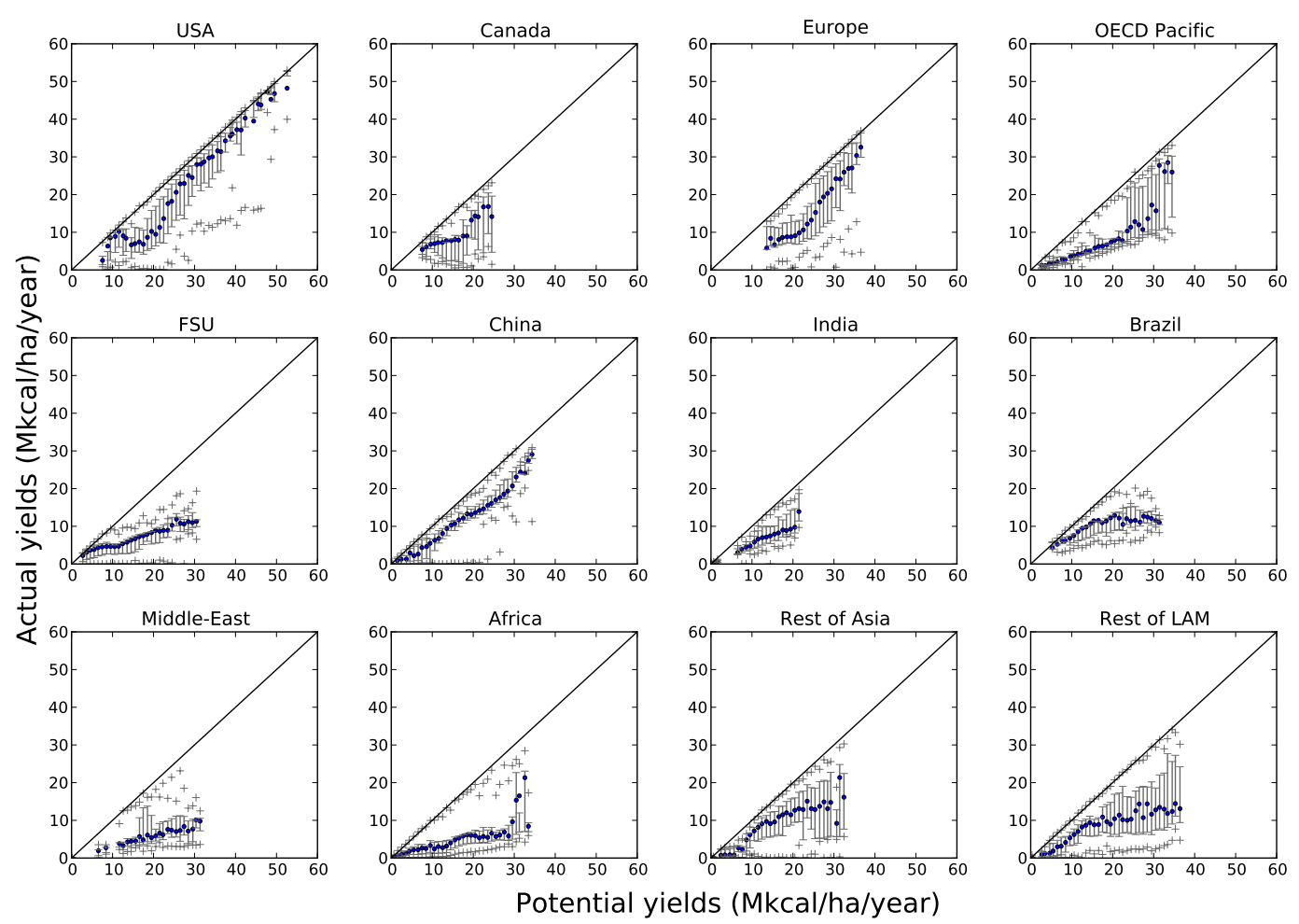

Fig. 9. Actual yield versus potential yield of dynamic crops within each potential yield class. Crosses are minimums and maximums, whiskers go from the 20th to the 80th percentile. X-axis in $\mathrm{GJ} \mathrm{ha}^{-1} \mathrm{yr}^{-1}$ ranges from 0 to 251. See Fig. 6 for a map of the difference between potential and actual yields of dynamic crops.

is added when additional residues and fodder are required by animals during a simulation, only cropland areas dedicated to fodder production inventoried by the FAO at the base year are included in the model in the other cropland category.

\subsection{Distribution of agricultural areas over land classes}

Cropland, pasture and forest areas are allocated to land classes according to the representative potential yields described in Sect. 3.1.

Based on the distinction between the extensive and intensive livestock production systems, the Nexus Land-Use models the production frontier between the two systems according to economic principles inspired by the Ricardian theory. In this prospect, we consider a limit land class $j_{\text {limit }}$ splitting agricultural lands in two parts: a first one corresponding to the intensive system where land classes have the highest potential yields and a second one corresponding to the extensive system, on lands with lower productivity (see Fig. 11). In this theoretical framework, croplands are supposed to be located on the intensive system where lands are more productive. Hence, at the base year, we assigned the least productive lands to the extensive system until the proportion of dynamic croplands become significant, the remaining part of the distribution being assigned to the intensive one. Cropland initially located in the extensive system - representing between

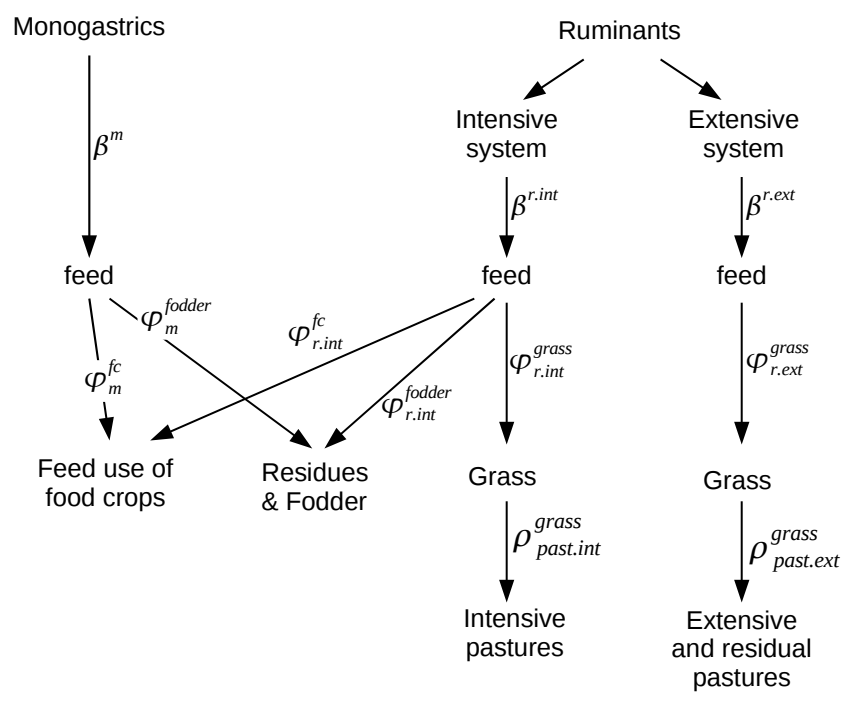

Fig. 10. Links between animal calorie production, feed categories and pasture areas. Reading: the amount of feed required to produce one calorie of monogastric is $\beta_{\mathrm{m}}$, split into a share $\phi_{\mathrm{m}}^{\mathrm{fc}}$ of food crops and $\phi_{\mathrm{m}}^{\text {fodder }}$ of crop residues and fodder. Values are reported in Tables 4,5 and 6 
Table 6. Consumed grass yield of intensive permanent pastures $\rho_{\text {past,int }}^{\text {grass }}$ in $\mathrm{Mkcal} \mathrm{ha}^{-1} \mathrm{yr}^{-1}$, intensive permanent pasture area $S_{\text {past,int }}$ in Mha, production of intensive ruminant meat and milk per hectare of intensive permanent pasture $\rho_{\text {past }}^{\text {rint }}\left(=\rho_{\text {past,int }}^{\text {grass }} /\left(\beta_{\text {r,int }} \phi_{\text {r,int }}^{\text {grass }}\right)\right)$ in $\mathrm{Mkcal} \mathrm{ha}^{-1} \mathrm{yr}^{-1}$. Consumed grass yield of extensive permanent pastures $\rho_{\text {past,ext }}^{\text {grass }}$ in $\mathrm{Mkcal} \mathrm{ha}^{-1} \mathrm{yr}^{-1}$, extensive permanent pasture area $S_{\text {past,ext }}$ in Mha and, production of extensive ruminant meat and milk per hectare of extensive permanent pasture $\rho_{\text {past }}^{\text {rext }}$ in $\mathrm{Mkcal}^{\text {ha }}{ }^{-1} \mathrm{yr}^{-1}$. Yield of pastures are the quantity of grass grazed on a unit of land and not the total grass grown.

\begin{tabular}{lrrrrrr}
\hline Regions & $\rho_{\text {past,int }}^{\text {grass }}$ & $S_{\text {past,int }}$ & $\rho_{\text {past }}^{\text {r,int }}$ & $\rho_{\text {past,ext }}^{\text {grass }}$ & $S_{\text {past,ext }}$ & $\rho_{\text {past }}^{\text {r,ext }}$ \\
\hline USA & 6.3 & 120 & 1.0 & 2.3 & 104 & 0.10 \\
Canada & 19.5 & 5 & 2.6 & 1.8 & 15 & 0.07 \\
Europe & 13.7 & 74 & 2.6 & 16.5 & 2 & 0.24 \\
OECD Pacific & 5.9 & 24 & 0.8 & 2.4 & 254 & 0.11 \\
FSU & 7.8 & 48 & 1.1 & 0.3 & 285 & 0.01 \\
China & 5.4 & 74 & 0.5 & 2.8 & 198 & 0.09 \\
India & 54.1 & 4 & 16.8 & 2.8 & 7 & 0.03 \\
Brazil & 22.8 & 25 & 0.9 & 6.4 & 151 & 0.08 \\
Middle East & 5.7 & 7 & 1.5 & 0.7 & 81 & 0.01 \\
Africa & 6.5 & 64 & 0.3 & 1.7 & 700 & 0.02 \\
Rest of Asia & 24.4 & 12 & 2.1 & 8.1 & 119 & 0.10 \\
Rest of LAM & 14.6 & 43 & 0.7 & 3.9 & 282 & 0.05 \\
\hline
\end{tabular}

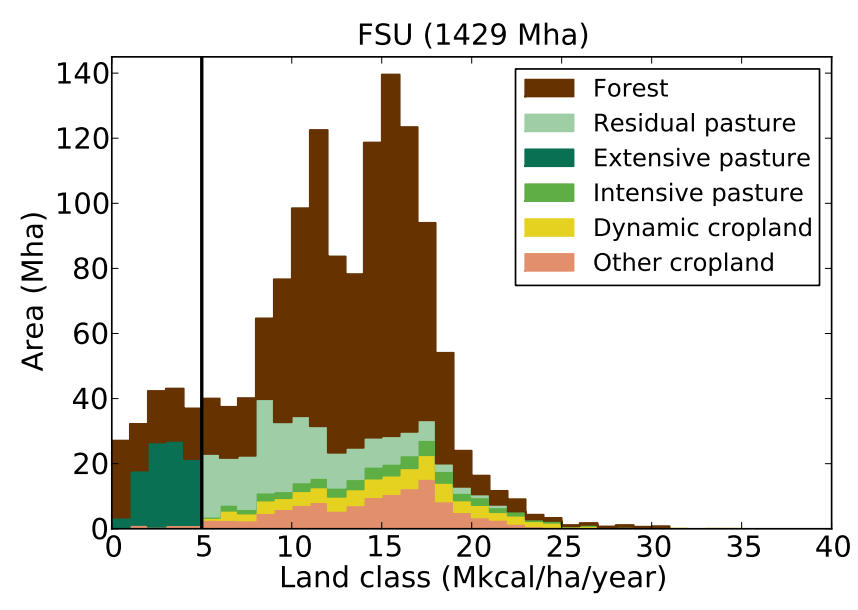

Fig. 11. Illustration of the production frontier (limit land class $j_{\text {limit }}$ ) on the histogram of the land area classes of potential yield in the former Soviet Union (black vertical bar). The intensive livestock system is located on the right of this frontier, and the extensive system on the left. When the profit of the intensive system increases relatively to the extensive one, $j_{\text {limit }}$ decrease to lower fertile land classes (the black vertical bar moves to the left in the figure) and the corresponding extensive pastures becomes part of the intensive system. In the opposite case, the frontier moves to more fertile land classes and the extensive system increases at the expense of the intensive one. For more details, see Sect. 2.4 and Eq. (23) in Sect. 4.3. $\mathrm{X}$-axis in $\mathrm{GJ} \mathrm{ha}^{-1} \mathrm{yr}^{-1}$ ranges from 0 to 167 .

0 to $11 \%$ of cropland area - are assigned to the other cropland category. The limit land class separating the two systems evolves during the simulation according to a cost minimisation criterion considering calorie and energy prices in a given region.
At the calibration, the distribution of permanent pastures over land classes is split into two land-use categories: extensive pastures are located to the left of the limit land class and intensive pastures, the areas given by Bouwman et al. (2005), are distributed into land classes proportionally to dynamic cropland (see Figs. 12 and 13).

In most regions, the area covered by pastures on high potential yield lands (to the right of the limit land class) is larger than the area of intensive pastures inventoried by Bouwman et al. (2005). The remaining pastures are referred to as residual pastures. Despite being located on the potential intensive side of the land distribution, we assume that these pastures have the same features as extensive ones. In the model, this use of land is assumed to be inefficient in the sense that production cost is not minimised. The residual pastures may correspond in reality to lands extensively managed because of geographic and institutional limitations (e.g. high transport cost, inadequate topography or specific land property rights, Merry et al., 2008).

\section{Economic drivers and model dynamics}

As a response to changes in the demand for agricultural biomass, with identified animal and vegetal calorie demands, the agricultural sector can adjust its production by either expanding agricultural lands over forest land or intensifying the production. Because land supply function is not implemented yet in the model, the expansion of agricultural land is constrained through prescribed deforestation scenarios in this study.

In Nexus Land-Use, the intensification of the production is driven up by two mechanisms: (i) increase in chemical 

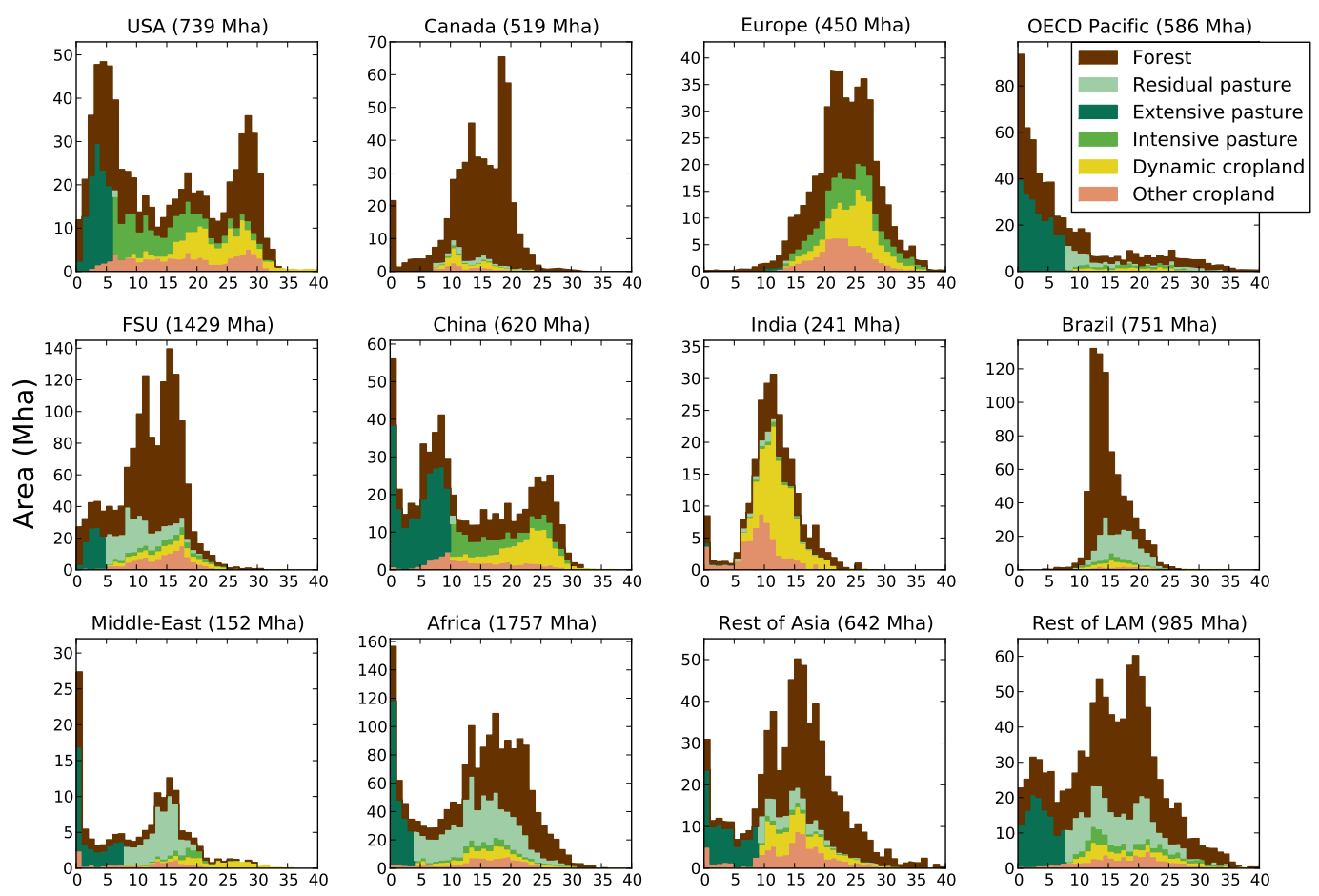

Land class (Mkcal/ha/year)

Fig. 12. Histogram of the land area classes of potential yield in the 12 Nexus Land-Use regions at the base year 2001. X-axis in GJ ha ${ }^{-1} \mathrm{yr}^{-1}$ ranges from 0 to 167 .

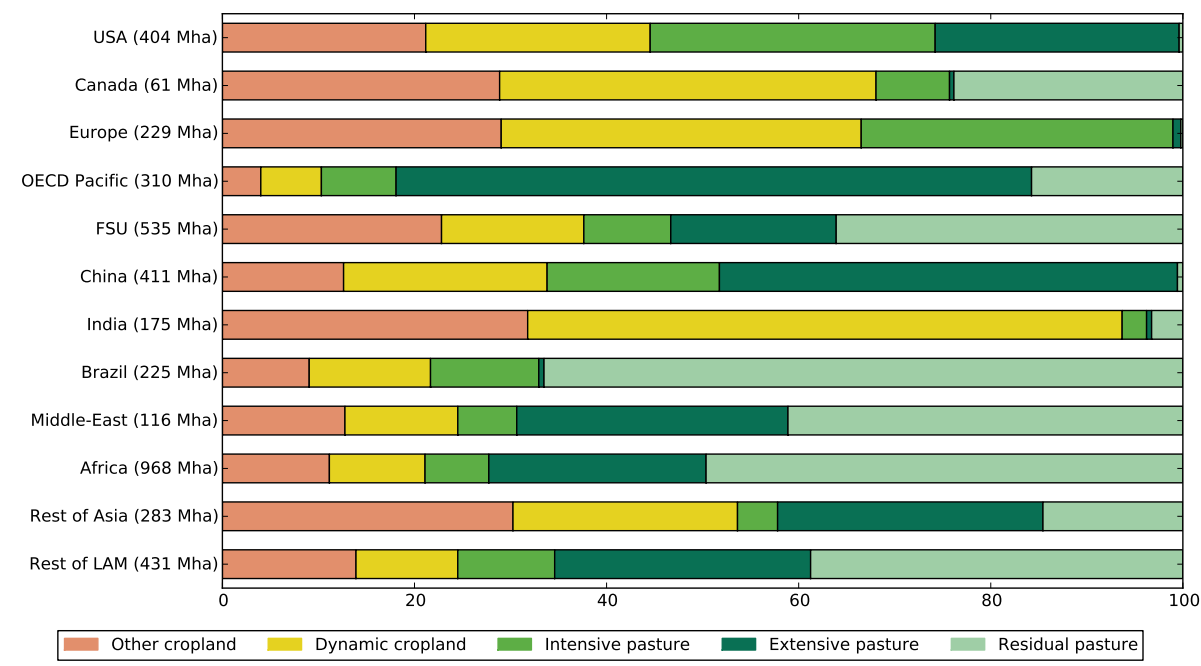

Fig. 13. Share of different agricultural land-use types in the 12 regions of the model at the base year 2001 .

fertilisers and pesticide inputs, (ii) replacement of biomass grazed by ruminants by concentrates, residues and fodder in animal feed composition. The first mechanism comes down to an increase of crop yield, and the second to a conversion of extensive into an intensive livestock production system. The intensification level that is achieved results from the minimisation of the total production cost.

\subsection{Crop production}

Crop yield increase with agricultural inputs (fertilisers and pesticides). Trade-offs between consumptions of labour and capital production factors are not represented in the model. Optimisation of costs thus results from our production function choice (see Sect. 3.2), which describes the biophysical 
Table 7. Compartmentalisation of food biomasses in Agribiom.

\begin{tabular}{|c|c|c|}
\hline Group & Compartments & SUA products lines (FAO Commodity Balances) \\
\hline $\begin{array}{l}\text { Plant products } \\
\text { (terrestrial) }\end{array}$ & Vege & $\begin{array}{l}\text { Wheat, rice and other grains of cereals; Bran; Maize and rice bran oils; } \\
\text { Beans, peas and other pulses; Cassava, potatoes and other roots or tu- } \\
\text { bers; Tomatoes, onions and other vegetables; Apple, oranges and other } \\
\text { fruit; Soya bean, cottonseeds, olives and other oilseeds or tree nuts with } \\
\text { their by-products (oils, cakes); Sugars and molasses; Wine, beer and } \\
\text { other; Cocoa, coffee and tea; Pepper, cloves and other spices. }\end{array}$ \\
\hline \multirow{2}{*}{$\begin{array}{l}\text { Animal } \\
\text { products } \\
\text { (terrestrial) }\end{array}$} & Rumi (grazing) & $\begin{array}{l}\text { Bovine meat, mutton, goat meat and other meat; Edible offal; Meat } \\
\text { meal; Milk (excluding butter), butter, ghee, cream; Raw animal fat. }\end{array}$ \\
\hline & Mono & Eggs, pig meat, poultry meat. \\
\hline \multirow{2}{*}{$\begin{array}{l}\text { Aquatic } \\
\text { products }\end{array}$} & Aqua & Freshwater fish \\
\hline & Mari & $\begin{array}{l}\text { Demersal fish, pelagic fish and other marine fish with their by products } \\
\text { (oils, meals); Crustaceans, cephalopods and other molluscs, aquatic } \\
\text { meat and plants. }\end{array}$ \\
\hline
\end{tabular}

dependency of yield on fertiliser and pesticide inputs. This comes down to implicitly considering that the decisions on labour and capital are independent from those on land and chemical inputs. In that, we assume that two choices are made, one for labour and capital, another for fertilisers, pesticides and land. In the model, we focus only on the second type of choice. As a consequence, substitutions that may exist between capital or labour and chemical inputs (e.g. herbicides reducing manual weed control) are not represented.

In each region, the annual cost function for a unit of cropland consists of

- A fixed cost per hectare per year FC corresponding to capital, non-mobile labour, business services and energy consumption for vehicles, buildings (heating, etc.) and other on-farm operations (drying of crops, etc.).

- An aggregate cost per hectare and per year for intermediate consumption of fertilisers and pesticides, denoted for each land class $j \operatorname{IC}_{j}\left(\rho_{j}\right)$ and characterised by decreasing returns. $\operatorname{IC}_{j}\left(\rho_{j}\right)$ is defined as the inverse of the production function described in Sect. 3.2 and shown in Eq. (13). It presents the following mathematical form:

$$
\operatorname{IC}_{j}\left(\rho_{j}\right)=\alpha_{\mathrm{IC}}\left(\rho_{j}^{\max }-\rho_{j}^{\min }\right)\left(\frac{\rho_{j}^{\max }-\rho_{j}^{\min }}{\rho_{j}^{\max }-\rho_{j}}-1\right) .
$$

- $p_{\chi}$ is the price index of fertilisers and pesticides intermediate consumption. Its evolution is derived from the energy prices trajectories computed by the Imaclim- $R$ model.

This function is such that $\operatorname{IC}_{j}^{\prime}\left(\rho_{j}\right)>0$ and $\operatorname{IC}_{j}^{\prime \prime}\left(\rho_{j}\right) \leq 0$. Calibration of the initial slope $\alpha_{\mathrm{IC}}$ (in $\$ \mathrm{Mkcal}^{-1}$ ) is detailed in Sect. 5.2.

\subsection{Livestock production}

The production of meat and eggs from monogastric animals is assumed to take place exclusively in the intensive type of production system. On the other hand, the production of ruminant meat and dairy takes place in either the extensive or the intensive system. In neither system is grass directly priced, but the calorie price reflects its costs in terms of land or of fixed costs per hectare.

The area of extensive pasture on the land class $j$ is equal to the fraction $f_{j}^{\text {Pext }}$ of the total agricultural area. In the extensive system, animal feed composition consists mainly of grass (and scavenging in India) and does not rely on any food crops, fodder or residues. We assume that this grass is grown without using any fertilisers or pesticides. As explained in Sect. 3.4, a share of these extensive pastures is also located on the most productive side of the distribution. On each land class $j$, these residual pastures cover a fraction $f_{j}^{\text {Pres }}$ of the total agricultural area.

By contrast, in the intensive ruminant production system, animals are fed by food crops - in a proportion $\phi_{\mathrm{r}, \text { int }}^{\mathrm{fc}}-$ grass, scavenging, animal products, residues and fodder (see Fig. 10). Food crops grown for feeding ruminants are produced in association with food crops production for human use on the fractions $f_{j}^{\text {crop }}$ of agricultural area and necessitate a consumption of fertilisers and pesticides $p_{\chi} \operatorname{IC}_{j}\left(\rho_{j}\right)$ in $\$ \mathrm{ha}^{-1} \mathrm{yr}^{-1}$.

To account for costs other than fertilisers or pesticides, we use a specific method as no database distinguishes between the intensive and extensive livestock production system costs. We define a variable $\mathrm{FC}_{\text {tot }}$ that also incorporates the fixed cost of crop production FC. This variable is used to compare the opportunity cost of the intensive and extensive systems and can be interpreted either as the difference between the fixed cost per hectare in the extensive and in the 
intensive system or as the fixed cost in the intensive system, considering that this cost is negligible in the extensive one. This cost determines the limit land class between the intensive and extensive sectors. It is calibrated to meet the base year land distribution described in Sect. 3.4.

\subsection{Minimisation program}

The limit land class index between the extensive system and the intensive one is denoted $j_{\text {limit }}$ and the upper bound of the land distribution is denoted $j_{\max }$. Overall, the cost minimisation of the total production yields:

$$
\begin{aligned}
& \text { Min } \\
& \rho_{j}, j_{\text {limit }}, D_{\mathrm{r}, \text { int }}^{\mathrm{fc}} \\
& Q_{\text {r,int }}, Q_{\text {r,ext }}, D_{\text {surf }} \\
& \left(\int_{\text {limit }}^{j_{\max }}\left(p_{\chi} \mathrm{IC}_{j}\left(\rho_{j}\right)+\mathrm{FC}_{\text {tot }}\right) f_{j}^{\text {crop }} \mathrm{d} j\right) D_{\text {surf }} \\
& Q_{\mathrm{other}}^{\mathrm{fc}}+\int_{j_{\text {limit }}}^{j_{\mathrm{max}}} f_{j}^{\mathrm{crop}} \rho_{j} d j D_{\text {surf }} \\
& =\left(D_{\mathrm{r}, \text { int }}^{\mathrm{fc}}+D_{\mathrm{h}+\mathrm{m}+\text { agro }}^{\mathrm{fc}}\right)\left(1+\omega_{\mathrm{swo}}^{\mathrm{fc}}\right) \\
& Q_{\mathrm{r}}=Q_{\mathrm{r} \text {,int }}+Q_{\mathrm{r} \text {,ext }} \\
& Q_{\mathrm{r}, \mathrm{ext}}=\left(\int_{0}^{j_{\text {limit }}} f_{j}^{\text {Pext }} d j+\int_{j_{\text {limit }}}^{j_{\text {max }}} f_{j}^{\text {Pres }} \mathrm{d} j\right) \rho_{\text {past }}^{\text {r,ext }} D_{\text {surf }} \\
& Q_{\mathrm{r}, \text { int }}=\frac{D_{\mathrm{r}, \text { int }}^{\mathrm{fc}}}{\beta_{\mathrm{r}, \text { int }} \phi_{\mathrm{r}, \mathrm{int}}^{\mathrm{fc}}} \\
& S_{\text {surf }}=D_{\text {surf }} \text {. }
\end{aligned}
$$

Variables are defined in Sect. 2.2 and in Table 9. As a reminder, all variables of this program are regional. Equations (16) to (20) display the constraints of the minimisation program. Equation (16) relates to the constraint on food crop production, $D_{\mathrm{h}+\mathrm{m}+\text { agro }}^{\mathrm{fc}}$ gathering the other types of demand than feed use for ruminant animals (human, feed use for monogastrics, etc.). Equation (17) corresponds to the constraint on global ruminant production. Equation (18) is the constraint on ruminant production on extensive and residual pastures. Production of meat and milk per hectare of extensive pasture $\rho_{\text {past }}^{\text {rext }}$ is considered to be constant over all land classes without consideration of corresponding potential yields for crops (Sect. 5.4). Equation (19) is the constraint on the intensive ruminant production from feed. Finally Eq. (20) provides the constraint on land availability.

The system is solved using the Lagrange multipliers method. The Lagrangian multiplier associated with the first constraint corresponds to the calorie price. The first order conditions on $\rho_{j}$ is that the calorie price $p_{\text {cal }}$ must be equal to the derivative of the function $\mathrm{IC}_{j}\left(\rho_{j}\right)$, linking fertilising and pesticide applications to yield, times the cost of these inputs:

$p_{\text {cal }}=p_{\chi} \mathrm{IC}_{j}^{\prime}\left(\rho_{j}\right)$.

The multipliers associated with the second, the third and the fourth constraint can be interpreted as the ruminant prices (global and for the extensive and intensive system). The solving of the minimisation program yields that these three multipliers are equal to each other. Hence, the price of a ruminant calorie is the same whether it is produced in the extensive system or in the intensive one. In the following, we denote it $p_{\mathrm{r}}$. First order conditions on $D_{\mathrm{r}, \mathrm{int}}^{\mathrm{fc}}$ leads to

$p_{\mathrm{r}}=p_{\mathrm{cal}}\left(1+\omega_{\mathrm{swo}}^{\mathrm{fc}}\right) \beta_{\mathrm{r}, \text { int }} \phi_{\mathrm{r}, \text { int }}^{\mathrm{fc}}$.

The limit between the intensive and the extensive system is given by the equality of profits in both production systems obtained through the first order conditions on $j_{\text {limit }}$ :

$$
\begin{gathered}
\left(p_{\text {cal }} \rho_{j_{\text {limit }}}-p_{\chi} \mathrm{IC}_{j_{\text {limit }}}\left(\rho_{j_{\text {limit }}}\right)-\mathrm{FC}_{\text {tot }}\right) f_{j_{\text {limit }}}^{\text {crop }}+ \\
p_{\mathrm{r}} f_{j_{\text {limit }}^{\text {Pres }}}^{\text {rext }} \rho_{\text {past }}^{\text {rext }}=p_{\mathrm{r}} f_{j_{\text {limit }}^{\text {Pext }}}^{\text {Pext }} \rho_{\text {past }}^{\text {reet }} .
\end{gathered}
$$

This relation can be easily interpreted. The intensive livestock production system is more productive than the extensive one because its productivity is linked to crop yield. On the other hand, it is also more costly because it requires more inputs and production factors. This sets a trade-off between the two systems: on high potential yield land classes, the productivity of the intensive system more than offsets its costs, making it more profitable; on the contrary, on low potential yield land classes, the extensive system will be more profitable, due to its costs and grass yield less dependent on the quality of land. The limit land class index between both systems $j_{\text {limit }}$ is thus defined as the land (or land class in a discrete representation) over which the profit is equivalent between producing intensively or extensively, and where Eq. (23) holds. In our theoretical framework, $j_{\text {limit }}$ corresponds to the Ricardian production frontier which moves towards less fertile land classes as the pressure on land grows.

As shown in Eq. (23), a fraction of extensive production $p_{\mathrm{r}} f_{j_{\text {limit }}}^{\text {Pres }} \rho_{\text {past }}^{\text {rext }}$ remains in the intensive livestock production system. This residual pasture production reflects the fact that some deviations from Ricardian theory may exist, preventing a clear segmentation between the intensive and extensive livestock production systems. These deviations can be related for example to geographic constraints such as accessibility issues, or to institutional distortions, such as flawed land property rights laws. We suppose that tensions on the agricultural system will encourage the policy makers to reduce those inefficiencies (by e.g. building better infrastructures or undertaking institutional reforms). For this reason, as mentioned in Sect. 2.4, the area of residual pastures in each land class get reduced as soon as the pressure on land, measured by the variations of $j_{\text {limit }}$, is higher than its reference level for year 2001. The conversion speed is linearly related with $j_{\text {limit }}$. 
Table 8. Calibrated calorie price $p_{\text {cal }}$ value in $2001\left(\$ \mathrm{Mkcal}^{-1}\right)$, calibrated initial slope of the production function $\alpha_{\mathrm{IC}}$ in $\$ \mathrm{Mkcal}^{-1}$ and GTAP 2001 intermediate consumption $\mathrm{IC}_{\chi}$ in billions of dollars

\begin{tabular}{lrrr}
\hline Regions & $p_{\text {cal }}$ & $\alpha_{\mathrm{IC}}$ & $\mathrm{IC}_{\chi}$ \\
\hline USA & 13.45 & 1.66 & 6.46 \\
Canada & 17.30 & 3.60 & 1.32 \\
Europe & 15.79 & 3.33 & 8.00 \\
OECD Pacific & 27.96 & 12.44 & 2.28 \\
FSU & 17.64 & 7.37 & 4.73 \\
China & 15.76 & 2.53 & 7.10 \\
India & 7.56 & 2.27 & 2.41 \\
Brazil & 15.70 & 2.87 & 1.77 \\
Middle East & 31.61 & 20.30 & 1.49 \\
Africa & 5.93 & 3.79 & 1.43 \\
Rest of Asia & 12.38 & 2.44 & 3.13 \\
Rest of LAM & 13.14 & 4.12 & 2.67 \\
\hline
\end{tabular}

To simplify the resolution, the fractions $f_{j_{\text {limit }}}^{\text {crop }}, f_{j_{\text {limit }}}^{\text {Pres }}$ and $f_{j \text { limit }}^{\text {Pext }}$ in Eq. (23) are taken to be the share of each land type in its corresponding production system $\left(f_{j_{\text {limit }}}^{\text {Pext }}\right.$ is thus equal to one). Indeed, it avoids the computationally very expensive sorting of profits of each land class. It is also consistent with a view in which the trade-off is made between each system as a whole.

The multiplier associated with Eq. (20) can be interpreted as the shadow price of land. Finally, the expression of land rent denoted $\lambda$ is the following:

$$
\begin{aligned}
\lambda & =p_{\text {cal }} \int_{j_{\text {limit }}}^{j_{\max }} f_{j}^{\mathrm{crop}} \rho_{j} \mathrm{~d} j-\int_{j_{\text {limit }}}^{j_{\max }}\left(p_{\chi} \mathrm{IC}_{j}\left(\rho_{j}\right)+\mathrm{FC}_{\mathrm{tot}}\right) f_{j}^{\mathrm{crop}} \mathrm{d} j \\
& +p_{\mathrm{r}}\left(\int_{0}^{j_{\text {limit }}} f_{j}^{\text {Pext }} d j+\int_{j_{\text {limit }}}^{j_{\text {max }}} f_{j}^{\text {Pres }} d j\right) \rho_{\text {past }}^{\text {r,ext }}
\end{aligned}
$$

Following the Ricardian theory, the land rent is as a surplus paying "the original and indestructible powers of the soil" (Ricardo, 1817) that reflects the scarcity and the heterogeneous quality of land.

\subsection{International trade}

The trade of both food crops (for human as well as animal use) and ruminant calories are considered in our model. Trade of monogastrics is considered constant at its 2001 level. Indeed, it essentially takes place in regions where monogastric animals are industrially produced and where the share of residues and fodder in the feed ration $\left(\phi_{\mathrm{m}, k}^{\text {fodder }}\right)$ is small. Yet, in the Nexus Land-Use modelling framework where residues and fodder are considered to be free - the higher the $\phi_{\mathrm{m}, k}^{\text {fodder }}$ the lower the price will be. Hence, the price of monogastric products does not account well for the propensity of a region to export. We hypothesise that this simplification does not significantly influence the results of the model because the demand for monogastric products is converted into a demand for food crops for feed use for which trade is modelled.

The representations of trade for food crops and ruminant products rely on the same modelling principles. For this reason, we detail only the trade for food crops in this section.

Agricultural commodities can be considered to be perfect substitutes for merchandise of the same kind supplied by any other country. Therefore, the international trade is modelled by using a pool representation without any consideration of the geographic origin of goods: the global demand for imports of calories is aggregated into a single set of homogeneous goods and shared among regions according to export functions.

Demand for imports is supposed to be driven by price ratios taking into account food sovereignty and security considerations: the share of the domestic demand which is supplied by imports is supposed to be a growing functions of price ratios between domestic and world prices. Hence, even if domestic price happens to be higher than world price, a share of the demand remains domestically produced.

Export shares are solely determined by relative prices, using functions reflecting the imperfect competition on the international markets of agricultural goods. As previously mentioned, the sources of imperfect competition are not related with the place of production of the goods, but to other reasons such as import barriers or export tariffs.

More specifically, imports of food crops for each region are calculated by addressing the regional demand to a pool according to a share function based on the regional calorie price $p_{\mathrm{cal}_{k}}$ and the world calorie price $p_{\mathrm{cal}}^{\mathrm{w}}$ defined as follows:

$p_{\mathrm{cal}}^{\mathrm{W}}=\sum$ ShareExp $_{k} \times p_{\mathrm{cal}_{k}}$

where ShareExp $\operatorname{Sis}_{k}$ is the export share of region $k$ in the pool. It is set equal to $\frac{\alpha_{k}^{\exp } p_{\mathrm{cal}_{k}}^{-2}}{\sum_{k} \alpha_{k}^{\exp } p_{\mathrm{cal}_{k}}^{-2}}$. Import and export functions for region $\mathrm{k}$ are thus given by

$\operatorname{Imp}_{k}^{\mathrm{fc}}=\alpha_{k}^{\mathrm{imp}} \times \frac{p_{\mathrm{cal}_{k}}}{p_{\mathrm{cal}}^{\mathrm{W}}} \times D_{k}^{\mathrm{fc}}$

$\operatorname{Exp}_{k}^{\mathrm{fc}}=\frac{\alpha_{k}^{\exp } p_{\mathrm{cal}_{k}}^{-2}}{\sum_{k} \alpha_{k}^{\exp } p_{\mathrm{cal}_{k}}^{-2}} \times \sum_{k} \operatorname{Imp}_{k}^{\mathrm{fc}}$

$\alpha_{k}^{\text {exp }}$ and $\alpha_{k}^{\text {imp }}$ are regional coefficients calibrated on actual import and export volumes from the Agribiom database in 2001. Exports of agricultural goods present the particular feature that they are all the more restricted than there is tension on food security. Export bans that occurred during the 2008 food crisis in several countries (India, Brazil, Kenya, etc.), or more recently in Russia after the heat wave of summer 2010, are characteristic examples (Demeke et al., 2009). To reflect such food security concerns for the long-term, export capacities for food crops are incorporated and defined as 
Table 9. Main notations. Except $p_{\mathrm{cal}}^{\mathrm{w}}$, they are all regional. $(t)$ means evolving through the simulation. $j$ is the subscript of land classes.

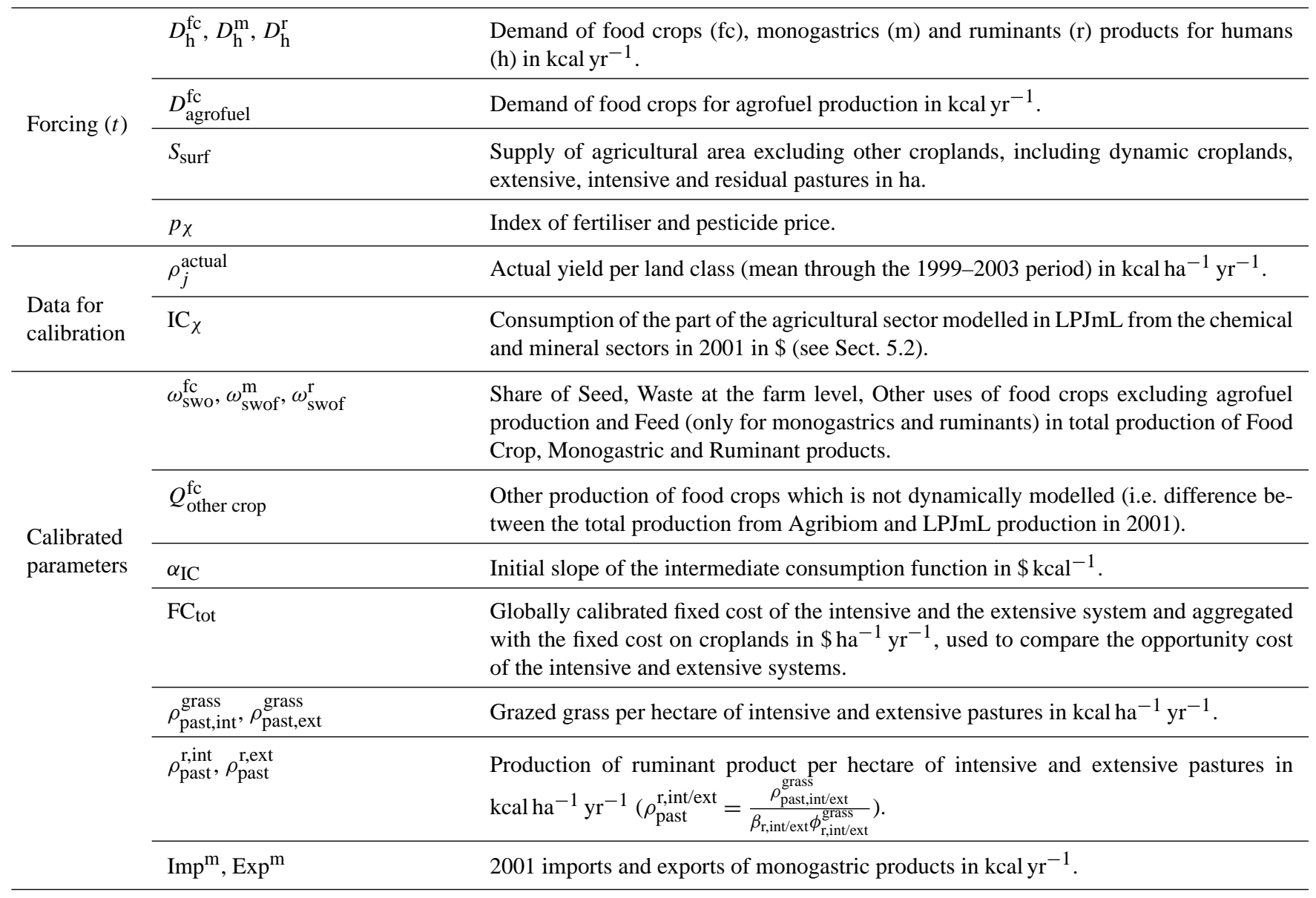

the gap between the potential production $\sum \rho_{j, k}^{\max } f_{j, k}^{\mathrm{crop}} S_{\text {surf, } k}$ and the domestic demand for plant food.

In accordance with the facts, this representation allows a region to simultaneously import and export a same category of goods, and countries facing different production costs may be present on the market. Another consequence of this modelling choice for international trade is related to the aggregation in calories. Indeed, the simultaneous imports and exports may also be interpreted as underlying fluxes of different commodities that we do not try to model separately.

\section{Model calibration}

Unless otherwise specified, the model parameters are calibrated against agricultural and economical statistics (Agribiom, GTAP) for base year 2001 in each region (see Table 9 for a list of calibrated parameters). This section describes the Agribiom data set, which provides to the Nexus Land-Use data of food supply and use for the base year.

\subsection{World supply and use of crop calories}

Each year, the Nexus Land-Use model calculates a global biomass balance (Fig. 3) equalising the annual flows of edible biomass which are produced, traded and consumed. The balance is expressed in kilocalories by aggregating many different products according to their origin (plants, ruminants, etc.), and not in tons of biomass for a range of commodities, as in most other economic models.

From a single country to the whole world, Agribiom generates synthetic and coherent estimates on the past (Dorin, 2011) and can be used to simulate and explore future possible resource-use balances of edible biomass. Its construction was initiated in 2006 with the aim of creating a tool for use in collective scenario-building such as Agrimonde (Paillard et al., 2011) and in hybrid modelling exercises such as the one presented in this paper. The basic principle of Agribiom is to link human food diets with spaces (crops, pastures, freshwater, continental shelves, etc.) supplying edible biomass (grain, tuber, fruit, vegetable, milk, meat, fish, etc.) through resource-use balances in kilocalories that take into account trade between countries. Such balances were 
Table 9. Continued.

\begin{tabular}{|c|c|c|}
\hline \multirow{3}{*}{$\begin{array}{l}\text { Biophysical } \\
\text { parameters }\end{array}$} & \multirow{2}{*}{$\begin{array}{l}\rho_{j}^{\max }, \rho_{j}^{\min } \\
\beta_{\mathrm{m}}, \beta_{\mathrm{r}, \text { int }}, \beta_{\mathrm{r}, \mathrm{ext}}\end{array}$} & \multirow{2}{*}{$\begin{array}{l}\text { Potential yield and minimum (no inputs) yield }\left(\rho_{j}^{\min }=0.1 \times \rho_{j}^{\max }\right) \text { in } \mathrm{kcal} \mathrm{ha}^{-1} \mathrm{yr}^{-1} \\
\text { Feed conversion factor for monogastrics, intensive and extensive ruminants in kcal o } \\
\text { feed/kcal of animal product. }\end{array}$} \\
\hline & & \\
\hline & $\begin{array}{ll}\phi_{\mathrm{m}}^{\mathrm{fc}}, & \phi_{\mathrm{m}}^{\mathrm{fodder}}, \\
\phi_{\mathrm{r}, \text { int }}^{\mathrm{fc}}, & \phi_{\mathrm{r}, \text { int }}^{\text {fodder }}, \\
\phi_{\mathrm{r}, \text { int }}^{\text {grass }}, & \phi_{\mathrm{r}, \text { ext }}^{\text {grass }}\end{array}$ & $\begin{array}{l}\text { Share of feed categories in animal rations (fc: food crops, fodder: residues and fodder, } \\
\text { grass: pasture grass, monog: monogastrics, r,int: intensive ruminants, r,ext: extensive } \\
\text { ruminants). }\end{array}$ \\
\hline \multirow{3}{*}{$\begin{array}{l}\text { Variables } \\
\text { depending } \\
\text { on land } \\
\text { classes }(t)\end{array}$} & $\rho_{j}$ & Yield of the land class $j$ minimizing farmer's production cost in $\mathrm{kcal} \mathrm{ha}^{-1} \mathrm{yr}^{-1}$. \\
\hline & $\mathrm{IC}_{j}$ & $\begin{array}{l}\text { Intermediate consumption of chemical and mineral inputs of the land class } j \text { in } \\
\$ \mathrm{ha}^{-1} \mathrm{yr}^{-1} \text {. }\end{array}$ \\
\hline & $\begin{array}{l}f_{j}^{\text {crop }}, f_{j}^{\text {Pint }}, f_{j}^{\text {Pres }} \\
f_{j}^{\text {Pext }}\end{array}$ & $\begin{array}{l}\text { Area of dynamic cropland (i.e. where crops modelled in the LPJmL model are grown), } \\
\text { intensive pastures, residual pastures, extensive pastures of the land class } j \text { expressed as } \\
\text { a fraction of } D_{\text {surf. }}\end{array}$ \\
\hline \multirow{11}{*}{$\begin{array}{l}\text { Variables } \\
(t)\end{array}$} & $p_{\mathrm{cal}}$ & Food crop calorie price in $\$ \mathrm{kcal}^{-1}$. \\
\hline & $\lambda$ & Land rent in $\$ \mathrm{ha}^{-1} \mathrm{yr}^{-1}$. \\
\hline & $p_{\mathrm{r}}$ & Price of ruminant calories in $\$ \mathrm{kcal}^{-1}\left(=p_{\mathrm{cal}}\left(1+\omega_{\mathrm{swo}}^{\mathrm{fc}}\right) \beta_{\mathrm{r}, \text { int }} \phi_{\mathrm{r}, \text { int }}^{\mathrm{fc}}\right)$. \\
\hline & $p_{\mathrm{cal}}^{\mathrm{w}}$ & World calorie price in $\$ \mathrm{kcal}^{-1}$. \\
\hline & $j_{\text {limit }}$ & Limit land class. \\
\hline & $D_{\text {surf }}$ & $\begin{array}{l}\text { Demand of agricultural area excluding other croplands, including dynamic croplands, } \\
\text { extensive, intensive and residual pastures in ha. }\end{array}$ \\
\hline & $Q_{\mathrm{r}, \text { int }}, Q_{\mathrm{r}, \mathrm{ext}}, Q_{\mathrm{r}}$ & 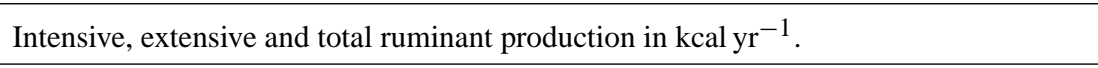 \\
\hline & $D_{\mathrm{m}}^{\mathrm{fc}}, D_{\mathrm{r}, \text { int }}^{\mathrm{fc}}$ & Demand of food crops for monogastrics and intensive ruminant production in $\mathrm{kcal}^{\mathrm{yr}} \mathrm{r}^{-1}$. \\
\hline & $D^{\mathrm{fc}}$ & Total demand of food crops in $\mathrm{kcal} \mathrm{yr}^{-1}$. \\
\hline & $\operatorname{Imp}^{\mathrm{fc}}, \operatorname{Exp}^{\mathrm{fc}}$ & 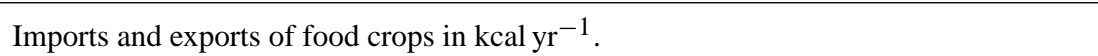 \\
\hline & $\operatorname{Imp}^{r}, \operatorname{Exp}^{r}$ & 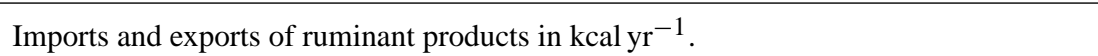 \\
\hline
\end{tabular}

estimated since 1961 for five categories of edible products: plant products from croplands, products from grazing (ruminant) and non-grazing (monogastric) animals, products from freshwater or sea water. They aggregate 109 agricultural products (or group of products) edible in their primary form and for which the FAO (2010) provides annual countrylevel Supply-Utilisation Accounts (SUA) in metric tones (Table 7).

The SUA volumes in tons are converted into kilocalories (kcal) via a process which uses nutritional coefficients provided by FAO (2001) or Gebhardt et al. (2006) and assumptions regarding the processing of primary products (e.g. soybean) into secondary products (e.g. soya oil and oilcake). The output in kilocalories is similar to the supply-utilisation accounts of FAO, but without a Processed column on the right side:
$Q_{\mathrm{AB}}^{i}-\operatorname{Exp}_{\mathrm{AB}}^{i}+\operatorname{Imp}_{\mathrm{AB}}^{i}+\delta_{\text {stock, } \mathrm{AB}}^{i}=D_{\mathrm{h}, \mathrm{AB}}^{i}+\mathrm{Feed}_{\mathrm{AB}}^{i}+$

Seed $_{\mathrm{AB}}^{i}+$ Waste $_{\mathrm{AB}}^{i}+$ Other $_{\mathrm{AB}}^{i}$

where:

- AB subscript stands for Agribiom.

- $i$ subscript is a category of food biomass: food crop (fc), ruminant (rumi) and monogastric (monog).

- $Q$ is the production (kcal).

- Exp is the exports (kcal).

- Imp is the imports (kcal).

- $\delta_{\text {stock, } \mathrm{AB}}^{i}$ is the stock variation (negative sign if destocking) (kcal). 
- $D_{\mathrm{h}, \mathrm{AB}}^{i}$ is the quantity used for feeding humans (kcal).

- Feed is the quantity used for feeding animals (kcal).

- Seed is the quantity used for reproductive purposes (seed, eggs, etc.) (kcal).

- Waste is the wasted quantity between the general available quantities (Production - Exports + Imports + $\Delta$ Stocks) and their allocation to a specific use (food, feed, etc.); note that this does not include losses occurring before and during harvesting, or wastage occurring in the household (kcal).

- Other is the quantity used for non-food purposes: lubricants, energy, etc. (kcal).

In the Nexus model, $\delta_{\text {stock, } A B}^{i}$ is neglected. The share of seed, waste at the agricultural stage and other non-food biomass is considered to be a constant fraction of the total crop production for all the simulation. This fraction is denoted $\omega_{\text {swo }}^{\text {fc }}$ and is defined in Eq. (29). Corresponding coefficients for monogastrics and ruminants are $\omega_{\text {swof }}^{\mathrm{m}}$ and $\omega_{\text {swof }}^{\mathrm{r}}$, which also accounts for feed use (whey, bone and fish meal, etc.).

$\omega_{\text {swo }}^{\mathrm{fc}}=\frac{\text { Seed }_{\mathrm{AB}}^{\mathrm{fc}}+\text { Waste }_{\mathrm{AB}}^{\mathrm{fc}}+\text { Other }_{\mathrm{AB}}^{\mathrm{fc}}}{D_{\mathrm{h}, \mathrm{AB}}^{\mathrm{fc}}+D_{\text {feed,AB }}^{\mathrm{fc}}+\operatorname{Exp}_{\mathrm{AB}}^{\mathrm{fc}}-\operatorname{Imp}_{\mathrm{AB}}^{\mathrm{fc}}}$

The consumption of crop products used as feed for livestock intensive systems is calculated using the production of monogastric and ruminant animals in the intensive system and Bouwman et al. (2005) conversion factors (see Eq. 30). The monogastric production statistics are taken from Agribiom. The ruminant production by the intensive system at the base year $Q_{\mathrm{r}, \mathrm{int}}^{2001}$ is diagnosed as a fraction of the total ruminant production of Agribiom according to data from Bouwman et al. (2005) on intensive grazing.

$Q_{\text {feed,2001 }}^{\mathrm{fc}}=Q_{\mathrm{m}}^{\mathrm{AB}} \beta_{\mathrm{m}} \phi_{\mathrm{m}}^{\mathrm{fc}}+Q_{\mathrm{r}, \text { int }}^{2001} \beta_{\mathrm{r}, \text { int }} \phi_{\mathrm{r}, \text { int }}^{\mathrm{fc}}$

As previously mentioned in Sect. 2.3, data from LPJmL do not cover all food crop production. The rest of the production is denoted $Q_{\mathrm{other} \mathrm{crop}}^{\mathrm{fc}}$. Evolution of the quantity produced on the other croplands category as well as its corresponding yields are forced by an external scenario. Its production at the base year is deduced from Eq. (31), as given by

$$
\begin{gathered}
Q_{\text {dyn crop }}^{\mathrm{fc}}+Q_{\text {other crop }}^{\mathrm{fc}}=\left(D_{\mathrm{h}, \mathrm{AB}}^{\mathrm{fc}}+D_{\text {feed,2001 }}^{\mathrm{fc}}+\operatorname{Exp}_{\mathrm{AB}}^{\mathrm{fc}}\right. \\
\left.-\mathrm{Imp}_{\mathrm{AB}}^{\mathrm{fc}}\right) \omega_{\text {swo }}^{\mathrm{fc}}
\end{gathered}
$$

where $Q_{\mathrm{dyn}}^{\mathrm{fc}}$ crop is the dynamic production calculated using actual yields.

\subsection{Calibration of the production function and the regional price of food crops calories for base year 2001}

In this section, we describe the calibration of the initial slope of the production function $\alpha_{\mathrm{IC}}$ and the calorie price $p_{\text {cal }}$ at base year 2001 in each region. This calibration is done in two steps. The assumptions that the minimum yields are equal to $10 \%$ of potential yield (see Sect. 3.2), implies that the yield value minimising farmers' cost is proportional to the potential yield values over each land class.

$\frac{\rho_{j}\left(p_{\mathrm{cal}}\right)}{\rho_{j}^{\max }}=1-(1-0.1) \sqrt{\frac{\alpha_{\mathrm{IC}} \times p_{\chi}}{p_{\text {cal }}}}$

To make possible the calibration of the production function, yields are firstly computed so that the total production remains equal to the base year production:

$\sum \rho_{j} f_{j}^{\text {crop }} S_{\text {surf }}=\sum \rho_{j}^{\text {actual }} f_{j}^{\text {crop }} S_{\text {surf }}$

To assess the validity of the resulting distribution of yields over land classes, correlation coefficients between computed base year yields $\rho_{j}$ and actual yields $\rho_{j}^{\text {actual }}$ from LPJmL are computed for each region. They are generally above 0.8 except for Brazil where the correlation coefficient is 0.69 , meaning that our linear model gives a good approximation of the reality. Then, the following system of equations is solved in $p_{\text {cal }}$ and $\alpha_{\mathrm{IC}}$ :

$$
\begin{array}{r}
\mathrm{IC}_{j}^{\prime}\left(\rho_{j}\right)=\alpha_{\mathrm{IC}}\left(\frac{\rho_{j}^{\max }-\rho_{j}^{\min }}{\rho_{j}^{\max }-\rho_{j}}\right)^{2}=\frac{p_{\text {cal }}}{p_{\chi}} \\
\sum_{j} p_{\chi} \mathrm{IC}_{j}\left(\rho_{j}\right) f_{j}^{\text {crop }} S_{\text {surf }}=\mathrm{IC}_{\chi} .
\end{array}
$$

Equation (34) results from the first order conditions for cost minimisation (see Sect. 4.3). In Eq. (35), the sum of the intermediate consumption of each land class is set equal to the intermediate consumption from $\mathrm{IC}_{\chi}$ coming from the GTAP 6 database (GTAP, 2006). $\mathrm{IC}_{\chi}$ is the regional consumption of the part of the agricultural sector modelled in LPJmL from the chemical and mineral sectors (Table 8). GTAP categories corresponding to the chemical and mineral sectors are: chemical, rubber, plastic products and mineral necessities. GTAP categories corresponding to the agricultural sector modelled in LPJmL are wheat, oil seeds, rice and cereal grain necessities. Sugar beet and sugar cane are aggregated into one single GTAP category. As sugar cane is not modelled in LPJmL, this category was removed in regions where sugar cane was believed to be in majority (India, Brazil, Rest of Asia, Rest of Latin America, Middle East, OECD pacific and Africa) and added elsewhere. The calibrated calorie price value in 2001 and the initial slope of the production function are presented in Table 8 .

\subsection{Calibration of fixed costs per hectare}

The parameter $\mathrm{FC}_{\text {tot }}$ is calibrated so as to ensure that at the base year the equality between costs in the intensive system and in the extensive one at the frontier $j_{\text {limit }}$ holds (see Sect. 4.3 Eq. 23). This yields: 


$$
\begin{aligned}
\mathrm{FC}_{\mathrm{tot}} & =p_{\text {cal }} \rho_{j_{\text {limit }}}-p_{\chi} \mathrm{IC}_{j_{\text {limit }}}\left(\rho_{j_{\text {limit }}}\right) \\
& +\frac{p_{\mathrm{r}} \rho_{\text {past }}^{\text {r,ext }}\left(f_{j_{\text {limit }}^{\text {Pext }}}^{\text {Pex }}-f_{j_{\text {limit }}^{\text {Pres }}}\right)}{f_{j_{\text {limit }}^{\text {crop }}}}
\end{aligned}
$$

\subsection{Adjustments to the livestock model}

In this section, we describe calculation of grass yield and modifications brought to Bouwman et al. (2005) feed conversion factor of intensive and extensive ruminants.

FAO statistics on animal products include a category called animal fat for which no breakdown between ruminant and monogastric animals is available. In Agribiom, this animal fat was entirely added to the ruminant production while Bouwman et al. (2005) ignore it. Therefore, to remain consistent with the Agribiom database, we modify the feed conversion factors for intensive and extensive ruminants $\beta_{\mathrm{r} \text {,ext }}$ and $\beta_{\mathrm{r} \text {,int }}$ to add this production of fat. Parameters of the Nexus Land-Use livestock production model are shown on Tables 4 and 5.

Potential yields apply only to dynamic cropland and are not used to calculate grass yields. In the Nexus Land-Use, the grass yields at the base year are calibrated as the ratio between grass needs and pasture areas in each livestock production system. The quantification of total permanent pasture area is highly uncertain due to the unclear distinction between rangeland and grassland pastures in national inventories (Ramankutty et al., 2008). The Ramankutty et al. (2008) data set is believed to be more reliable than the FAO statistics used by Bouwman because it combines satellite data and national inventories. For this reason, we calibrate the sum extensive and residual pastures area as the difference between total pasture area inventoried by Ramankutty et al. (2008) and the intensive pasture area from Bouwman et al. (2005). For each region of the model, the resulting extensive pasture area is combined with the total extensive ruminant grass consumption in the region, given by Bouwman et al. (2005), to obtain the yield of extensive pasture. In the same way, yield on intensive pastures is calculated by dividing the intensive ruminants grass consumption from Bouwman et al. (2005) with intensive pasture areas (Table 6). These pastures yields are the quantity of grass grazed (as opposed to total grass grown) on a unit of land.

\section{Example of model outputs}

\subsection{Scope, parameters and scenarios}

This section provides a sensitivity analysis giving some insights on the functioning of the model. To this end, we run the Nexus Land-Use until 2050 for different evolutions of the size of arable lands and of the values of energy and chemical inputs price $p_{\chi}$. For each of these simulations, food consumption increases following a scenario inspired by the Millennium Ecosystem Assessment scenario "Global Orchestration" (Millennium Ecosystem Assessment Board, 2005). Population grows according to the median scenario of the United Nations (United Nations, Department of Economic and Social affairs, Population Division, 2004) and agrofuel production is set constant at its 2001 level for the sake of simplicity. The maximal conversion speed of residual pastures is set to $20 \%$ per year. The area of the other cropland category and its corresponding production is fixed at its 2001 level.

In the model, adjustments to variations of production are governed by the evolutions of crop yields and the area of extensive pastures. Given their critical role, we present on Figs. 15 and 14 the 2050 values of these two key drivers resulting from each simulations. The evolutions of crop yields are represented using a world crop yield defined as the mean of each regional crop yield weighted by regional cropland areas. The area of extensive pastures is computed as the share of the area of extensive pastures in the total area of agricultural lands.

To exhibit the consequences of relaxing land pressure in the most readable way, we choose to crudely apply a same rate of expansion of agricultural lands to each of the 12 regions of the model, even if in some cases this scenario is not coherent with the actual evolution. In these simulations the selected expansion of agricultural areas between 2001 and 2050 ranges between 0 and $20 \%$.

The value of the fertiliser and pesticide price index $p_{\chi}$ is set equal to one at the base year in every regions of the model. For this sensitivity simulation, variations to 2050 range between $0 \%$ and $+200 \%$. Here again, we aim only at exploring the consequences of hypothetical variations of $p_{\chi}$ on the key drivers of the model, without particular regards to the realism of the envisaged evolutions. The run corresponding to $\mathrm{a}+100 \%$ increase in fertiliser and pesticide price index and an expansion of agricultural areas of $10 \%$ is detailed in Appendix A.

\subsection{Key results}

In the Nexus Land-Use, crop yields result from the tradeoff between land and chemical inputs prices. Hence, an increase of $p_{\chi}$ disadvantages the use of chemical inputs over land and generate a yield reduction ceteris paribus. This effect stands out clearly in Fig. 14. Conversely, as arable land becomes scarcer, its shadow costs $\lambda$ increase, favouring all other things being equal the use of chemical inputs and prompting up yield increase. The form of the layer indicates that land scarcity tends to reduce the elasticity of yield with respect to $p_{\chi}$, showing that as land pressure grows, the flexibility to choose yields considering chemical and energy prices diminishes. When the pressure on land is low, the elasticity of yields to $p_{\chi}$ is such that it brings out the nonlinear form of the crop production function (see Sect. 3.2). 


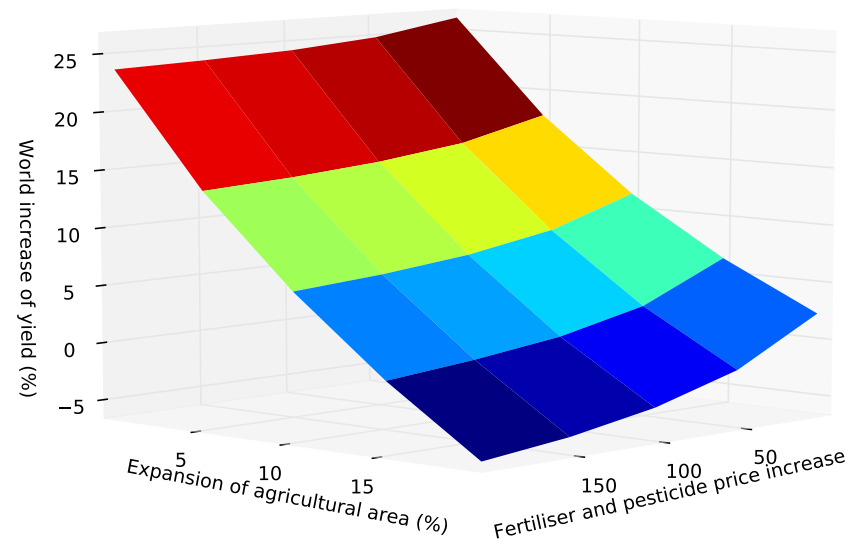

Fig. 14. Variations of crop yields in function of chemical inputs price and expansion rate of agricultural lands 2001 and 2050.

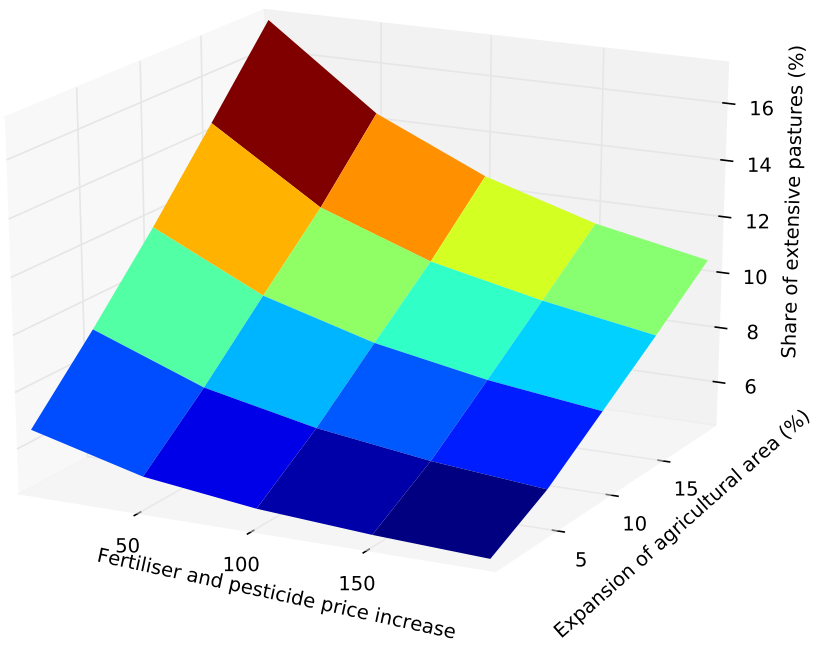

Fig. 15. Variations of the proportion of extensive pastures in function of chemical inputs price and expansion rate of agricultural lands between 2001 and 2050.

When the pressure on land peaks (at lowest rate of expansion of agricultural lands), this elasticity diminishes, revealing a smaller non-linearity. The volume of consumption of chemical inputs, also provided by the model, follows the same pattern as the yields: a doubling of $p_{\chi}$ induces a reduction of $4 \%$ of the 2050 chemical inputs consumption when the size of agricultural lands remains constant and a reduction of $11 \%$ with expansion of agricultural lands of $20 \%$.

Figure 15 shows that the proportion of extensive pastures diminishes as $p_{\chi}$ rises and as the deforestation rate drops. When $p_{\chi}$ increases, it is actually necessary to intensify the livestock production by converting extensive pastures into crop or intensive pastures, in order to compensate the loss of production due to the fall of yield resulting from the rise of $p_{\chi}$. Moreover, when the expansion of agricultural lands decreases and the arable lands become scarcer, the production must be intensified both by pushing up yields and by converting extensive pastures.

\section{Discussion}

The model presented here is at its first step of development and several paths of improvement are possible. In the current version of the model, the mix of cultivated crops is supposed to be constant over time. This implicitly accounts for agronomic choices, local preferences, cropping system (rotations) and so on. Nevertheless, this may lead to over- or underestimation of the potential yield. For example a scenario with a high demand for animal products should trigger a shift in production resulting in an increased share of a crop like maize in the crop mix. Such a shift should feedback on the potential yield, because of the better caloric productivity of this particular crop. Given the assumption of a constant mix of cultivated crops, the Nexus Land-Use cannot account for this effect. As the crop mix is composed of relatively homogeneous crops with respect to their yield, we consider that this error is not greater than the one we would have made by computing another mix of crops disconnected from the patterns previously mentioned. In future versions of the model, this issue could be overcome by modifying the potential yield according to the projected mix of crops. The land-use map used in the model is only one of the possible land use maps. The classification of pastures and forests may be different in other maps. For example, world pasture area would have been $70 \%$ larger if the Erb et al. (2007) land-use data set had been used.

The production function could be improved in several ways. This firstly concerns the representation of capital and labour. Even if it is not the main focus of the model, exploring the consequences of the agricultural intensification on the labour market could be interesting, especially in developing countries where agricultural manpower still constitutes an important share of the working population. Some ameliorations could also be brought to model manure use, which is for the moment simply incorporated in the calibration coefficients. Indeed, an increase of animal production also means an increase in available manure which could be substitutable to industrial fertilisers and allow for a reduction of intensification costs. Several solutions are possible, the simplest would be to index the coefficients of the production function on the animal production per cultivated hectares.

Modelling a Ricardian frontier makes it possible to represent the yield decrease resulting from the cultivation of lower quality lands. However, decision making in land-use does not exclusively follow Ricardian principles. There is a large diversity of factor influencing land allocation. For example, market imperfections, such as an opaque land market and a limited access to credit by farmers may limit an efficient use of land. Residual pastures is a land-use category on which the cost is not minimised and accounts in this way for 

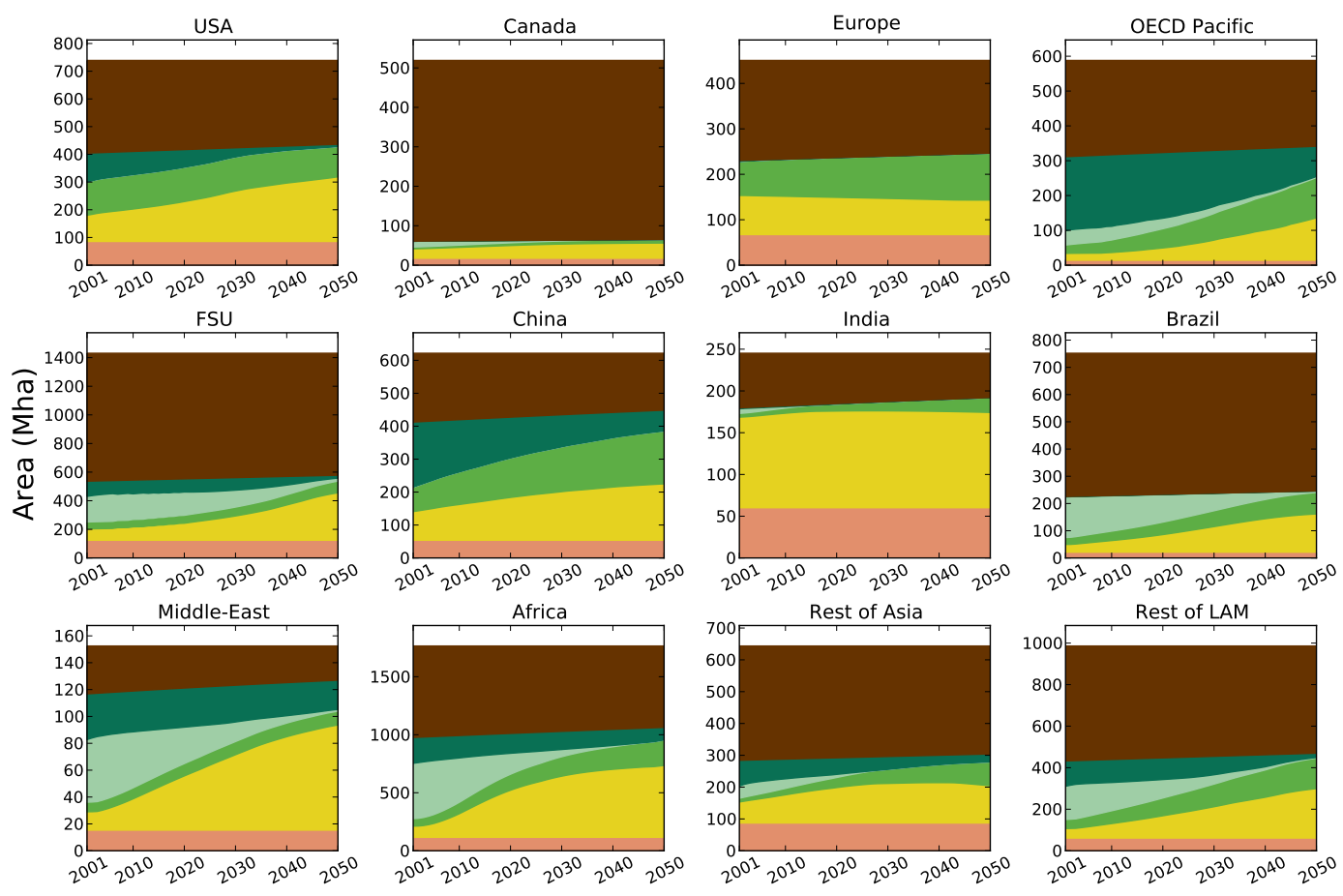

Forest $\quad$ Ext. pasture pasture

Int. pasture

Fig. 16. Land-use changes simulated by the Nexus Land-Use. Expansion of agricultural areas is set to $10 \%$ and fertiliser and pesticide price increases by $+100 \%$ up to 2050 .

some of these economic imperfections. Brazil - whose agricultural system is characterised by large market imperfections (de Gouvello et al., 2010; Merry et al., 2008) - appears to be the country with the largest share of residual pastures in the model (see Fig. 13). Regions with the lowest share of residual pastures are the USA, Europe, India and Asian countries. These regions have actually been at the cutting edge of the Green Revolution, which has favoured a more efficient use of land by, for example, improving the institutional environment (creation of rural financial institutions, etc.). Another deviation from Ricardian decision making is related to risk management by farmers. Rosenzweig and Binswanger (1993) highlighted the importance of this issue for understanding the allocation of production resources. For instance, risk aversion may explain why farmers - especially in developing countries - do not always use the optimal amount of fertilisers and pesticides. In spite of its importance, risk management is ignored in the Nexus Land-Use and should be a component of future development.

Finally, agronomic representation used in the Nexus LandUse is based on a distribution of land into land classes of potential yields which may not match reality, in part because they are based on a vegetation model, here LPJmL. As mentioned in Sect. 3.1, potential yields are not correct everywhere, notably because of issues on multi-cropping representation, the lack of perennial crops and errors due to the
LPJmL CFT approach. Also, potential yields are a theoretical construct based on many assumptions such as the variety parametrisation or photosynthetic efficiencies. More fundamentally, the Nexus Land-Use is designed within the green revolution paradigm based on the selection of varieties, use of chemical fertilisers and pesticide inputs and low labour intensive production, but ignores other promising possibilities such as agroecology (Francis et al., 2003; Wezel et al., 2009).

\section{Conclusions}

Interactions concerning food demand, biomass energy and forest at the global scale are subject to growing interest, especially regarding indirect land-use changes (Searchinger et al., 2008) and the consequences for food prices of agrofuel production and forest preservation (Baier et al., 2009; Tokgoz and Elobeid, 2006; Wise et al., 2009). This study presents a new global model approach to tackling this issue by providing a detailed representation of agricultural intensification mechanisms - which are viewed as a key driver to bridge conflicts on land-use (van Vuuren et al., 2009) - in a structure accounting for the main types of demand for biomass at the global scale.

In contrast to most land-use models, intensification is described in the Nexus Land-Use for food crops production, through the non-linear effect of an increase of chemical 

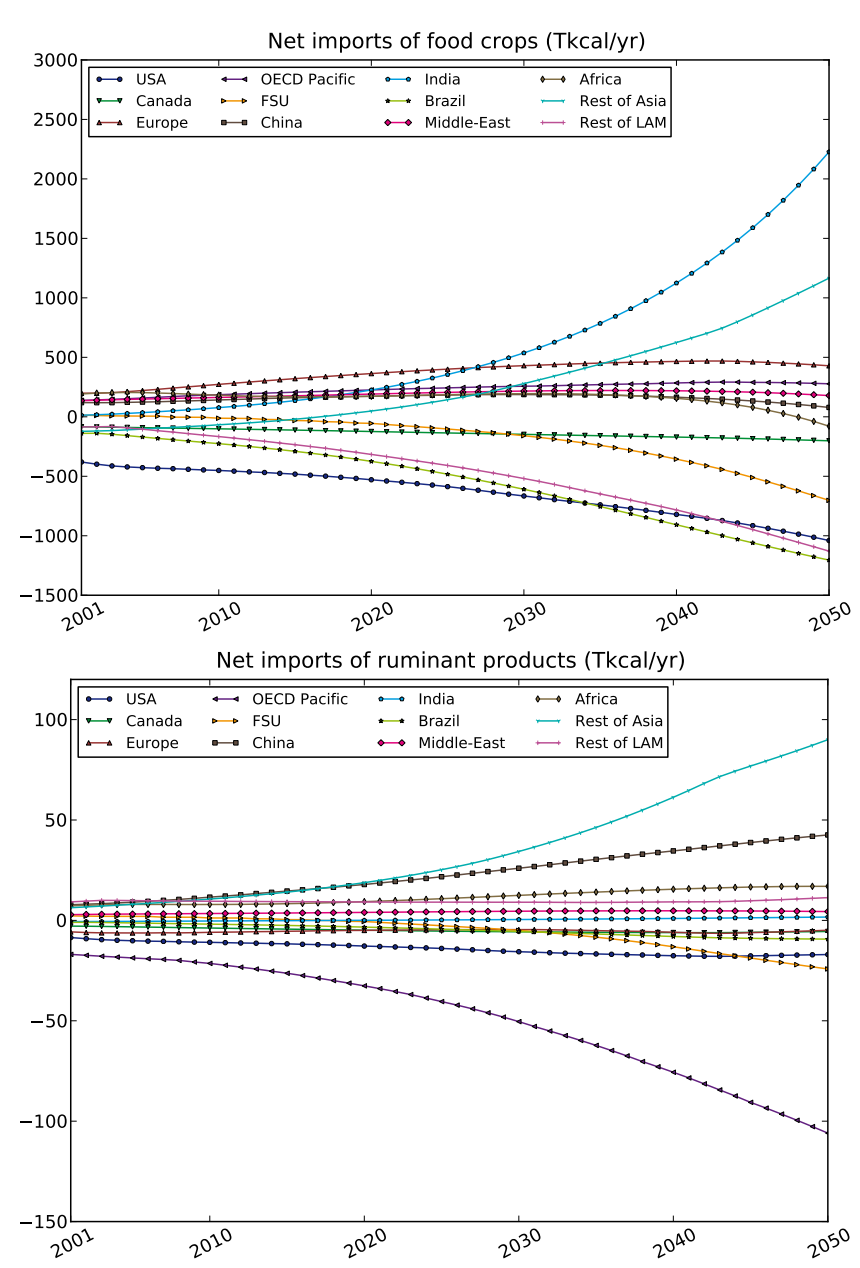

Fig. 17. Net imports of food crops (top), and ruminant products (bottom) resulting from the sample output run. 1 Tera kilo calorie $\left(10^{12} \mathrm{kcal}\right)=4.1868$ Peta Joules $\left(10^{15} \mathrm{~J}\right)$.

inputs, and for livestock production as well, through conversion of pasture into cropland according to a Ricardian logic taking into account sub-optimalities linked to geographic (e.g. accessibility) or institutional (e.g. land property rights) limitations. This description relies on a hybrid representation where intensification results from economic as well as biophysical processes, sharing some similarities with MAgPIE (Lotze-Campen et al., 2008) or GLOBIOM (Havlík et al., 2011).

This methodology has several advantages. First, the integration in the Nexus Land-Use model of regional land area distributions of potential yields and the modelling of a $\mathrm{Ri}$ cardian frontier of production make it possible to explicitly represent the variations of yield induced by the expansion of cropland on marginal lands. The relevance of representing such mechanism has already been shown in van Meijl et al. (2006). Secondly, technical change can be simulated both in agronomy - through a prescribed increase of potential yields
- and in zootechnics - through a change of livestock production model parameters.

The Nexus Land-Use framework makes it possible to explore jointly the effect of changes in food diet with respect to total calories and animal share, agrofuel production and deforestation in a context of changing energy price. Some sensitivity scenarios were explored with a special focus on the effect of future deforestation and rising energy prices on agricultural intensification. According to these results, an increase of energy price induces a yield reduction and a diminution of extensive pastures area. Reducing deforestation also decreases extensive pasture area but leads to a growing consumption of agricultural inputs. Most importantly, these results show that incorporating biophysical constraints in a land-use model generates a non-linear response of crop yield and extensive pastures area to variations of energy price and deforestation rate.

\section{Appendix A}

\section{Sample output run}

To illustrate the model functioning, this section details a run of the sensitivity analysis shown in Sect. 6. The selected run corresponds to an expansion of agricultural areas of $10 \%$ and to a fertiliser and pesticide price increase by $+100 \%$ up to 2050. Given our scenario of population and diet (see Sect. 6.1), the global food demand rises by $+60 \%$ for plant food products (which excludes feed) and by $+160 \%$ for animal products.

Figure 16 shows the land-use changes computed by the model in the 12 regions of the world. It exhibits a sharp increase in cropland area for most regions. In the model, the agricultural sector trades off between increasing yield by adding chemical inputs and expanding cropland area on extensively managed pastures (including residual pastures). As a result, regions with the highest share of extensive pasture OECD Pacific, Brazil, Middle East and Africa - experience the most significant evolution of cropland area from $+220 \%$ to $+300 \%$, while the distribution of agricultural area is almost steady in Europe and India where livestock production is exclusively intensive. Because the cropland expansion occurs mainly on extensive pastures which are mostly located on lower quality lands, the global average yield only increase by $2.5 \%$. Nonetheless, the global yield gap decreases from $47 \%$ to $42 \%$.

The world calory price increases threefold. Rises in food prices is more pronounced in India and the rest of Asia and is lowest in Brazil, the former Soviet Union (FSU) and Africa. India and the rest of Asia actually experience a strong increase in their food demand, especially with regards to animal products, and have relatively few productivity reserves be it in terms of yield gap or extensive pastures areas. Given these price evolutions, these two regions become 
major importers (importing respectively $58 \%$ and $40 \%$ of their consumption of food crops in 2050), while USA, FSU, Canada, rest of Latin America and Brazil are major exporters (exporting from $34 \%$ to $62 \%$ of their food crop production (Fig. 17).

Acknowledgements. This work was carried out within the GIS Climat Environnement Société DECLIC project. Authors thanks Lex Bouwman for providing data. Nicolas Viovy, Nicolas Vuichard, Thierry Doré, Laurence Roudart and Michel Griffon for their useful comments on the paper. Aude Valade and Donald White for their help on english language. Meriem Hamdi-Cherif for GTAP data processing. Cloé de Caudron de Coquereaumont for color choices.

Edited by: O. Boucher

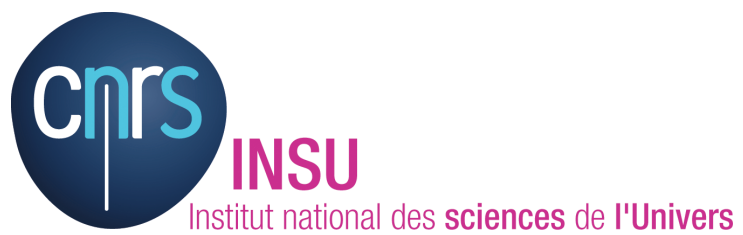

The publication of this article is financed by CNRS-INSU.

\section{References}

Baier, S., Clements, M., Griffiths, C., and Ihrig, J.: Biofuels impact on crop and food prices: using an interactive spreadsheet, International Finance Discussion Papers 967, Board of Governors of the Federal Reserve System (US), available at: http://www. federalreserve.gov/pubs/ifdp/2009/967/ifdp967.pdf (last access: 15 October 2012), 2009.

Bondeau, A., Smith, P. C., Saehle, S., Schaphoff, S., Lucht, W., Cramer, W., Gerten, D., Lotze-Campen, H., Müller, C., Reichstein, M., and Smith, B.: Modelling the role of agriculture for the 20th century global terrestrial carbon balance, Glob. Change Biol., 13, 679-706, doi:10.1111/j.13652486.2006.01305.x, 2007.

Bouwman, A., der Hoek, K. V., Eickhout, B., and Soenario, I.: Exploring changes in world ruminant production systems, Agr. Systems, 84, 121-153, doi:10.1016/j.agsy.2004.05.006, 2005.

Brenkert, A., Kim, S., Smith, A., and Pitcher, H.: Model Documentation for the MiniCAM, Tech. Rep. PNNL14337, Pacific Northwest National Laboratory, available at: http://www.pnl.gov/main/publications/external/ technical_reports/PNNL-14337.pdf (last access: 15 October 2012), 2003.

Briassoulis, H.: Analysis of Land Use Change: Theoretical and Modeling Approaches, Ph.D. thesis, Department of Geography, University of the Aegean, Lesvos, Greece, available at: http: //www.rri.wvu.edu/WebBook/Briassoulis/contents.htm (last access: 15 October 2012), 2000.

Brisson, N., Gary, C., Justes, E., Roche, R., Mary, B., Ripoche, D., Zimmer, D., Sierra, J., Bertuzzi, P., Burger, P., Bussière, F., Cabidoche, Y. M., Cellier, P., Debaeke, P., Gaudillère, J. P., Hénault, C., Maraux, F., Seguin, B., and Sinoquet, H.: An overview of the crop model, Euro. J. Agron., 18, 309-332, doi:10.1016/S1161-0301(02)00110-7, 2003.

Chavas, J.-P.: On the economics of agricultural production, Aust. J. Agr. Resour. Econom., 52, 365-380, 2008.

Crassous, R., Hourcade, J.-C., and Sassi, O.: Endogenous Structural Change and Climate Targets Modeling Experiments with Imaclim-R, Energy J., 27, 259-276, 2006.

de Gouvello, C., Filho, B. S. S., Nassar, A., Schaeffer, R., Alves, F. J., and Alves, J. W. S.: Brazil Low-carbon Country Case Study, Tech. rep., The International Bank for Reconstruction and Development, The World Bank, available at: http://siteresources.worldbank.org/BRAZILEXTN/ Resources/Brazil_LowcarbonStudy.pdf (last access: 15 October 2012), 2010.

Decreux, Y. and Valin, H.: MIRAGE, Updated Version of the Model for Trade Policy Analysis: Focus on Agriculture and Dynamics, Working Papers 7284, TRADEAG - Agricultural Trade Agreements, available at: http://ageconsearch.umn.edu/ bitstream/7284/2/wp070007.pdf (last access: 15 October 2012), 2007.

Demeke, M., Pangrazio, G., and Maetz, M.: Country responses to the food security crisis: Nature and preliminary implications of the policies pursued, Tech. rep., Food and Agriculture Organization of the United Nations, 2009.

Dorin, B.: Agribiom Caloric Balance Sheets, updated estimates from Paillard et al. 2011, 25-65, 2011.

Erb, K.-H., Gaube, V., Krausmann, F., Plutzar, C., Bondeau, A., and Haberl, H.: A comprehensive global $5 \mathrm{~min}$ resolution land-use data set for the year 2000 consistent with national census data, J. Land Use Sci., 2, 191-224, doi:10.1080/17474230701622981, 2007.

Fader, M., Rost, S., Müller, C., Bondeau, A., and Gerten, D.: Virtual water content of temperate cereals and maize: Present and potential future patterns, J. Hydrol., 384, 218-231, doi:10.1016/j.jhydrol.2009.12.011, 2010.

FAO, F.: Food Balance Sheets. A Handbook, Tech. rep., FAO, Rome, 2001.

FAO, F.: Statistical Database, available at: http://faostat.fao.org/ (last access: 15 October 2012), 2010.

Francis, C., Lieblein, G., Gliessman, S., Breland, T. A., Creamer, N., Harwood, R., Salomonsson, L., Helenius, J., Rickerl, D., Salvador, R., Wiedenhoeft, M., Simmons, S., Allen, P., Altieri, M., Flora, C., and Poincelot, R.: Agroecology: The Ecology of Food Systems, J. Sustain. Agr., 22, 99-118, doi:10.1300/J064v22n0310, 2003.

Gebhardt, S., Cutrufelli, R., Howe, J., Haytowitz, D., Pehrsson, P., Lemar, L., Holcomb, G., Nickle, M., Thomas, R., Exler, J., Showell, B., and Holden, J.: USDA National Nutrient Database for Standard Reference, Release 19, Tech. rep., USDA ARS, Washington DC., available at: http://www.nal.usda.gov/ fnic/foodcomp/Data/SR19/nutrlist/sr19w435.pdf (last access: 15 October 2012), 2006.

Godard, C., Roger-Estrade, J., Jayet, P., Brisson, N., and Bas, C. L.: Use of available information at a European level to construct crop nitrogen response curves for the regions of the EU, Agr. Systems, 97, 68-82, doi:10.1016/j.agsy.2007.12.002, 2008.

Golub, A., Hertel, T., and Sohngen, B.: Land Use Modeling in Recursively-Dynamic GTAP Framework, GTAP Working Papers 2609, Center for Global Trade Analysis, Department of Agricul- 
tural Economics, Purdue University, available at: https://www. gtap.agecon.purdue.edu/resources/download/3679.pdf (last access: 15 October 2012), 2008.

Gosme, M., Suffert, F., and Jeuffroy, M.-H.: Intensive versus low-input cropping systems: What is the optimal partitioning of agricultural area in order to reduce pesticide use while maintaining productivity?, Agr. Systems, 103, 110-116, doi:10.1016/j.agsy.2009.11.002, 2010.

GTAP: Global Trade, Assistance, and Production: The GTAP 6 Data Base, Tech. rep., Center for Global Trade Analysis, Purdue University, 2006.

Havlík, P., Schneider, U. A., Schmid, E., Böttcher, H., Fritz, S., Skalský, R., Aoki, K., Cara, S. D., Kindermann, G., Kraxner, F., Leduc, S., McCallum, I., Mosnier, A., Sauer, T., and Obersteiner, M.: Global land-use implications of first and second generation biofuel targets, Energy Policy, 39, 5690-5702, doi:10.1016/j.enpol.2010.03.030, 2011.

Heistermann, M., Müller, C., and Ronneberger, K.: Land in sight? Achievements, deficits and potentials of continental to global scale land-use modeling, Agriculture, Ecosyst. Environ., 114, 141-158, 2006.

Izaurralde, R., Williams, J., McGill, W., Rosenberg, N., and Jakas, M. Q.: Simulating soil C dynamics with EPIC: Model description and testing against long-term data, Ecol. Modell., 192, 362-384, doi:10.1016/j.ecolmodel.2005.07.010, 2006.

Lotze-Campen, H., Müller, C., Bondeau, A., Rost, S., Popp, A., and Lucht, W.: Global food demand, productivity growth, and the scarcity of land and water resources: a spatially explicit mathematical programming approach, Agr. Economics, 39, 325-338, 2008.

Merry, F., Amacher, G., and Lima, E.: Land Values in Frontier Settlements of the Brazilian Amazon, World Development, 36, 2390-2401, doi:10.1016/j.worlddev.2007.11.014, 2008.

Millennium Ecosystem Assessment Board: Ecosystems and Human Well-being: Scenarios, vol. 2, Island press, available at: http:// www.maweb.org/en/Scenarios.aspx, 2005.

Monfreda, C., Ramankutty, N., and Foley, J. A.: Farming the planet: 2. Geographic distribution of crop areas, yields, physiological types, and net primary production in the year 2000, Global Biogeochem. Cy., 22, GB1022, doi:10.1029/2007GB002947, 2008.

Paillard, S., Treyer, S., and Dorin, B. (Eds.): Agrimonde, Scenarios and Challenges for Feeding the World in 2050, Quae, Versailles, 2011.

Portmann, F. T., Siebert, S., and Döll, P.: MIRCA2000 - Global monthly irrigated and rainfed crop areas around the year 2000: A new high-resolution data set for agricultural and hydrological modeling, Global Biogeochem. Cy., 24, GB1011, doi:10.1029/2008GB003435, 2010.

Poulter, B., Ciais, P., Hodson, E., Lischke, H., Maignan, F., Plummer, S., and Zimmermann, N. E.: Plant functional type mapping for earth system models, Geosci. Model Dev., 4, 993-1010, doi:10.5194/gmd-4-993-2011, 2011.
Ramankutty, N., Evan, A. T., Monfreda, C., and Foley, J. A.: Farming the planet: 1 . Geographic distribution of global agricultural lands in the year 2000, Global Biogeochem. Cy., 22, GB1003, doi:10.1029/2007GB002952, 2008.

Ricardo, D.: On the principles of political economy and taxation, 1817.

Ronneberger, K., Berrittella, M., Bosello, F., and Tol, R.: KLUM@GTAP: Introducing Biophysical Aspects of Land-Use Decisions into a Computable General Equilibrium Model a Coupling Experiment, Environ. Modeling Assess., 14, 149-168, doi:10.1007/s10666-008-9177-z, 2009.

Rosenzweig, M. R. and Binswanger, H. P.: Wealth, Weather Risk and the Composition and Profitability of Agricultural Investments, Economic J., 103, 56-78, 1993.

Scouvart, M. and Lambin, É. F.: Approche systémique des causes de la déforestation en Amazonie brésilienne : syndromes, synergies et rétroactions, L'Espace géographique, available at: www.cairn. info/revue-espace-geographique-2006-3-page-241.htm (last access: 15 October 2012), 2006.

Searchinger, T., Heimlich, R., Houghton, R. A., Dong, F., Elobeid, A., Fabiosa, J., Tokgoz, S., Hayes, D., and Yu, T.-H.: Use of U.S. Croplands for Biofuels Increases Greenhouse Gases Through Emissions from Land-Use Change, Science, 319, 1238-1240, doi:10.1126/science.1151861, 2008.

Tokgoz, S. and Elobeid, A.: Analysis of the Link between Ethanol, Energy, and Crop Markets, An, Center for agricultural and rural development (card) publications, Center for Agricultural and Rural Development (CARD) at Iowa State University, available at: http://econpapers.repec.org/RePEc:ias:cpaper:06-wp435 (last access: 15 October 2012), 2006.

United Nations, Department of Economic and Social affairs, Population Division: World population to 2300, Tech. rep., United Nations, New York, available at: http://www.un.org/esa/population/ publications/longrange2/WorldPop2300final.pdf (last access: 15 October 2012), 2004.

van Meijl, H., van Rheenen, T., Tabeau, A., and Eickhout, B.: The impact of different policy environments on agricultural land use in Europe, Agr. Ecosyst. Environ., 114, 21-38, doi:10.1016/j.agee.2005.11.006, 2006.

van Vuuren, D., Faber, A., Langeweg, F., Maas, R., and van Dieren, W.: Growing within Limits. A Report to the Global Assembly 2009 of the Club of Rome, Tech. rep., Netherlands Environmental Assessment Agency (PBL), Bilthoven, 2009.

Wezel, A., Bellon, S., Doré, T., Francis, C., Vallod, D., and David, C.: Agroecology as a science, a movement and a practice. A review, Agron. Sustain. Develop., 29, 503-515, doi:10.1051/agro/2009004, 2009.

Wise, M., Calvin, K., Thomson, A., Clarke, L., Bond-Lamberty, B., Sands, R., Smith, S. J., Janetos, A., and Edmonds, J.: Implications of Limiting $\mathrm{CO}_{2}$ Concentrations for Land Use and Energy, Science, 324, 1183-1186, doi:10.1126/science.1168475, 2009. 